\title{
EL DERECHO FUNDAMENTAL A UNA SOCIEDAD LIBRE DE CORRUPCIÓN: UNA CONTRIBUCIÓN DESDE LATINOAMÉRICA
}

\author{
THE FUNDAMENTAL RIGHT TO A CORRUPTION-FREE SOCIETY: \\ A CONTRIBUTION FROM LATIN AMERICA
}

\author{
Roberto Carlos Fonseca Luján \\ Universidad Nacional Autónoma de México
}

Fecha de recepción: 2-5-19

Fecha de aceptación: 21-1-20

Resumen: Dentro de los trabajos del enfoque basado en derechos humanos sobre la corrupción, la posición más adelantada ha propuesto la existencia de un derecho humano a una sociedad libre de corrupción. La cuestión sobre este nuevo derecho continúa abierta; su existencia no se ha rebatido con solidez, ni se ha fundamentado de manera satisfactoria. El artículo se dirige a esta cuestión. Tras revisar el estado de la discusión sobre los vínculos entre derechos humanos y corrupción, se aportan razones en favor del reconocimiento de este derecho. Asimismo, se comenta la contribución del constitucionalismo latinoamericano reciente al tema, que ya ha consagrado en algún caso a la libertad frente a la corrupción como derecho fundamental.

Abstract: Within the human rights-based approach studies of corruption, the most advanced position has proposed the existence of a human right to a corruptionfree society. The new right question continues open because its existence neither has been refuted with solidity nor satisfactorily grounded. The article addresses this issue. Firstly, the state of the discussion on the links between human rights and corruption is reviewed. Secondly, reasons in favor of the recognition of this new right are given. Also, the recent Latin American constitutionalism's contribution, which has already recognized in some cases the freedom from corruption as a fundamental right, is commented.

Palabras clave: anticorrupción, derechos humanos, sociedad libre de corrupción Keywords: anti-corruption, human rights, corruption-free society

ISSN: 1133-0937

DERECHOS Y LIBERTADES

DOI: https://doi.org/10.20318/dyl.2021.5855

Número 44, Época II, enero 2021, pp. 237-275 


\section{INTRODUCCIÓN}

La corrupción se ha posicionado como uno de los temas más relevantes en la agenda internacional durante las últimas décadas. Su combate ha pasado de ser una preocupación económica y de gobernabilidad, a un asunto de política criminal. Recientemente, se le ha planteado también como un concepto de interés para los estudios de derechos humanos, en tanto se le reconoce como una amenaza para la vigencia y el goce de estos. El grupo de estudios que plantean este último abordaje al problema de la corrupción se identifican con la etiqueta de "enfoque basado en derechos humanos sobre la corrupción" 1 .

Dentro de estos estudios, la postura más adelantada ha propuesto que se reconozca la existencia de un derecho humano a la libertad frente a la corrupción o a sociedades libres de corrupción. El debate sobre esta propuesta no se ha generalizado, aunque hay razones para considerar su pertinencia. El presente artículo se dirige a esa discusión, replanteando los argumentos en favor de la propuesta de reconocimiento de este derecho humano.

Para presentar los argumentos, se requiere realizar el siguiente recorrido. La sección 2 revisa las generalidades de los estudios del enfoque basado en derechos humanos sobre la corrupción, destacando sus principales impulsores y sus campos de interés. La sección 3 comenta los efectos de la corrupción en los derechos humanos, según han sido descritos por estos trabajos a partir de dos tesis centrales: primera, que la corrupción produce un efecto negativo en los derechos; y segunda, que todos los actos de corrupción afectan o amenazan en algún grado a los derechos.

La sección 4 discute el problema de la redefinición de la corrupción como una violación de derechos humanos por sí misma, explicando los tres argumentos que la sostienen: el argumento de la corrupción sistémica como una negación del Estado constitucional, el argumento de la corrupción como

1 En general los autores hacen uso de categorías como "international human rights approach", "human rights-based approach" o "perspectiva de derechos humanos" para denominar esta propuesta de abordaje sobre la corrupción. Véanse Z. PEARSON, “An international human rights approach to corruption", en P. LARMOUR y N. WOLANIN (eds.), Corruption and Anti-Corruption, ANU Press, Canberra, 2001, pp. 30-61; M. BOERSMA y H. NELEN (eds.), Corruption \& Human Rights: Interdisciplinary Perspectives, Intersentia, Antwerp, 2010, passim; C. ROSE, "Limitations of a Human Rights Approach to Corruption", International and Comparative Law Quarterly, vol. 65, 2016, pp. 405-438; C. NASH, "Derechos Humanos y Corrupción. Un enfoque multidimensional”, Estudios de Derecho, núm. 165, 2018, pp. 139-162; A. PETERS, "Corruption as a Violation of International Human Rights", The European Journal of International Law, vol. 29, núm. 4, 2018, pp. 1251-1287.

DERECHOS Y LIBERTADES

ISSN: 1133-0937

Número 44, Época II, enero 2021, pp. 237-275

DOI: https://doi.org/10.20318/dyl.2021.5855 
una violación de la libertad, y el argumento de la corrupción como freno del desarrollo económico y social.

Con estas bases teóricas, la sección 5 examina la tesis de la existencia de un derecho humano a una sociedad libre de corrupción. Para esto, se confrontan las dos tesis principales que niegan la posibilidad de considerar este derecho, y se replantean los argumentos que han ofrecido sus proponentes. Este replanteamiento se realiza a partir de consideraciones de la teoría de los derechos morales. De acuerdo con esto, se encuentra que el derecho a una sociedad libre de corrupción surge de una doble fuente conceptual: deriva de otros derechos humanos ya reconocidos, y constituye un derecho correlativo del deber estatal de erradicar la corrupción sistémica.

Finalmente, la sección 6 comenta dos ejemplos constitucionales en Latinoamérica, en los que ya se ha expresado en el texto de la ley fundamental la relación entre corrupción y derechos humanos. Se trata de la constitución local de la Ciudad de México de 2017, que establece que el combate a la corrupción es pilar de un buen gobierno y garantía del derecho a la buena administración; y de la Constitución de Ecuador de 2008, que ha ido un paso más allá al reconocer de manera expresa el derecho fundamental a vivir en una sociedad democrática y libre de corrupción.

\section{EL ENFOQUE BASADO EN DERECHOS HUMANOS SOBRE LA CORRUPCIÓN}

La perspectiva de estudios sobre la corrupción basada en los derechos humanos es todavía minoritaria comparada con otros enfoques sobre el tema de la corrupción más desarrollados, como los estudios económicos ${ }^{2} \mathrm{o}$ los estudios jurídico-penales. Sus impulsores han sido particularmente organismos internacionales especializados en los temas de derechos humanos que han emitido los documentos fundamentales de esta perspectiva, como el Consejo Internacional de Políticas de Derechos Humanos ${ }^{3}$ [ICHRP], el

2 Los estudios en las ciencias sociales y económicas sobre el fenómeno de la corrupción han seguido cuatro enfoques principales: el modelo de la búsqueda de rentas; la teoría del agente principal; el funcionalismo y el enfoque del nuevo institucionalismo económico. Véase L. PELLEGRINI, Corruption, Development and the Environment, Springer, Netherlands, 2011, pp. 3-5.

Véanse Corruption and Human Rights: Making the Connection, International Council on Human Rights Policy, Transparencia Internacional, Ginebra, 2009; La integración de los derechos 
Programa de Desarrollo, la Comisión de Derechos Humanos del Consejo Económico y Social, y el Consejo de Derechos Humanos, entre otros órganos de Naciones Unidas ${ }^{4}$, junto con los comentarios de académicos publicados en las últimas dos décadas. En el ámbito regional latinoamericano, se ha sumado recientemente a este discurso la Comisión Interamericana de Derechos Humanos $[\mathrm{CIDH}]^{5}$.Como primer obstáculo, los estudios de este enfoque se enfrentan al hecho de que, en el ámbito del derecho internacional, los principales tratados en materia de corrupción no mencionan los derechos humanos y viceversa (con alguna excepción ${ }^{6}$ ); se trata de dos áreas jurídicas clara-

humanos en la agenda de combate a la corrupción: Retos, Posibilidades y Oportunidades, Consejo Internacional de Políticas de Derechos Humanos, Fundar, Ginebra, 2011.

4 Véanse fundamentalmente The impact of corruption on the human rights based approach to development, United Nations Development Programme, Oslo Governance Centre, 2004; La corrupción y sus repercusiones en el pleno disfrute de los derechos humanos, en particular los derechos económicos, sociales y culturales. Informe preliminar de la Relatora Especial, Sra. Christy Mbonu, Comisión de Derechos Humanos, 7 julio 2004, E/CN.4/Sub.2/2004/23; La corrupción y sus repercusiones en el pleno disfrute de los derechos humanos, en particular los derechos económicos, sociales y culturales, Comisión de Derechos Humanos, 5 agosto 2005, E/CN.4/Sub.2/2005/L.24/ Rev.1; Informe resumido acerca de la mesa redonda sobre las consecuencias negativas de la corrupción en el disfrute de los derechos humanos, Consejo de Derechos Humanos, 18 abril 2013, A/ HRC/23/26; Resolution 69/199. Preventing and combating corrupt practices and the transfer of proceeds of corruption, facilitating asset recovery and returning such assets to legitimate owners, in particular to countries of origin, in accordance with the United Nations Convention against Corruption, General Assembly, 18 diciembre 2014, A/RES/69/199; Resolution 29/11. The negative impact of corruption on the enjoyment of human rights, Human Rights Council, 22 julio 2015, A/HRC/ RES/29/11; Informe final del Comité Asesor del Consejo de Derechos Humanos sobre las consecuencias negativas de la corrupción en el disfrute de los derechos humanos, Consejo de Derechos Humanos, 5 enero 2015, A/HRC/28/73; Mejores prácticas para luchar contra las consecuencias negativas de la corrupción en el disfrute de todos los derechos humanos. Informe del Alto Comisionado de las Naciones Unidas para los Derechos Humanos, Consejo de Derechos Humanos, 15 abril 2016, $\mathrm{A} / \mathrm{HRC} / 32 / 22$.

5 Véanse Resolución 1/17 Derechos humanos y lucha contra la impunidad y la corrupción, Comisión Interamericana de Derechos Humanos, 12 de septiembre de 2017; Resolución 1/18 Corrupción y Derechos Humanos, Comisión Interamericana de Derechos Humanos, $167^{\circ}$ Período de Sesiones, Bogotá, 2 de marzo de 2018. Sobre los estándares definidos por la CIDH en estas resoluciones véase: M. MORALES ANTONIAZZI, “Aproximación a los estándares interamericanos sobre corrupción, institucionalidad democrática y derechos humanos", en C. TABLANTE y M. MORALES ANTONIAZZI (eds.), Impacto de la corrupción en los derechos humanos, Instituto de Estudios Constitucionales del Estado de Querétaro, México, 2018, pp. 335-366.

6 Se tienen menciones expresas en la Convención de la Unión Africana para la Prevención y la Lucha contra la Corrupción, de 2003. En Europa, se apunta que: “[L]a corrupción constituye una amenaza para la primacía del derecho, la democracia y los de-

DERECHOS Y LIBERTADES

ISSN: 1133-0937

Número 44, Época II, enero 2021, pp. 237-275

DOI: https://doi.org/10.20318/dyl.2021.5855 
mente separadas ${ }^{7}$. No obstante, la idea de la existencia de una relación entre los derechos humanos y la corrupción ha tenido eco paulatinamente en el discurso de agentes protagonistas del movimiento internacional anticorrupción, como Transparencia Internacional $[\mathrm{TI}]^{8}$, por lo que es previsible que los estudios desde esta perspectiva tiendan a aumentar.

¿Cuál es el método y, en su caso, los hallazgos de este enfoque? A partir de la definición de Human Rights Based Approach to Development elaborada por el Alto Comisionado de Naciones Unidas, se señala que el enfoque basado en derechos humanos sobre la corrupción propone ser un marco conceptual para el estudio del fenómeno de la corrupción y su combate, que se funda normativamente en los estándares internacionales de derechos humanos y se dirige operativamente a proteger y promover los derechos humanos ${ }^{9}$.

El problema detonante de estos estudios ha sido la identificación de los múltiples vínculos existentes entre derechos humanos y corrupción. El vínculo más comentado es el impacto que un acto de corrupción o la generalización de estos en una determinada sociedad producen en el goce y ejercicio

rechos humanos". Convenio Penal sobre la Corrupción (Convenio n. ${ }^{\circ} 173$ del Consejo de Europa), Estrasburgo, 27 enero 1999, Preámbulo. Por otro lado, el Prefacio de Kofi ANAN a la Convención contra corrupción señala: “La corrupción es una plaga insidiosa que tiene un amplio espectro de consecuencias corrosivas para la sociedad. Socava la democracia y el estado de derecho, da pie a violaciones de los derechos humanos". Convención de las Naciones Unidas contra la Corrupción. Resolución 58/4, Asamblea General, 31 octubre 2003.

7 La posición de la Corte Interamericana de Derechos Humanos -y en general de los tribunales internacionales de derechos humanos- ha sido terminante al respecto, al guardar una suerte de silencio prudente, evitando hacer referencias al "vínculo" entre corrupción y violaciones de derechos humanos, aun cuando en diversos casos podría haber elementos para hacer manifestaciones al respecto. En algún caso reciente se menciona ya la corrupción, pero sólo para hacer reenvío a los deberes de los Estados previstos en los tratados de ese terreno. El estudio del Centro de Derechos Humanos de la Universidad de Chile es muy interesante, pues ofrece un detallado recuento de las diversas sentencias en las cuales la Corte Interamericana "podría" haberse manifestado sobre la corrupción, pero se abstuvo de hacerlo. Véase C. NASH et al., Corrupción y Derechos Humanos: Una mirada desde la Jurisprudencia de la Corte Interamericana de Derechos Humanos, Centro de Derechos Humanos, Facultad de Derecho de la Universidad de Chile, Chile, 2014. Véanse también A. S. CLAVIJO CASTAÑEDA, "Actos de corrupción como violación a los derechos humanos", Saber, Ciencia y Libertad, vol. 7, núm. 1, 2012, pp. 35-45; M. MORALES ANTONIAZZI, “Aproximación a los estándares interamericanos sobre corrupción, institucionalidad democrática y derechos humanos", cit., pp. 356-360.

Véanse Los derechos humanos y la corrupción, Transparencia Internacional, Documento de trabajo 05, 2008; Declaración contra la corrupción, Transparencia Internacional.

9 Cfr. The impact of corruption on the human rights based approach, cit., p. 4.

ISSN: 1133-0937

DOI: https://doi.org/10.20318/dyl.2021.5855
DERECHOS Y LIBERTADES

Número 44, Época II, enero 2021, pp. 237-275 
de alguno o varios derechos humanos. En general, estos estudios asumen que ese impacto es preponderantemente negativo ${ }^{10}$. A la luz de ese vínculo negativo, se plantea algún intento de ajustar el concepto de corrupción, para redefinirla como una violación de derechos humanos ${ }^{11}$.

Otras relaciones se establecen no directamente desde los actos de corrupción, sino por vía de las políticas anticorrupción, que pueden entrar en tensión con ciertos derechos (como los derechos de los acusados de corrupción ${ }^{12}$ ), o impulsar directamente el fortalecimiento de otros ${ }^{13}$. Los escritos de este enfoque también suelen proponer líneas de acción para contribuir a la lucha anticorrupción, de acuerdo con las confluencias ${ }^{14}$ y puntos en común entre las agendas anticorrupción y pro-derechos ${ }^{15}$, así como complementando la vía penal ${ }^{16}$, por medio de la exigibilidad de responsabilidades estatales en el marco del derecho internacional garante de los derechos ${ }^{17}$. Sobre la "utilidad" práctica de estas propuestas, hay autores que ofrecen comentarios escépticos, dudando si el enfoque de derechos humanos puede contribuir a

10 Véase infra Apartado 3.

11 Véase infra Apartado 4.

12 Como en el caso de medidas legales, policiales o judiciales que pueden comprometer la presunción de inocencia o el debido proceso. Véase La integración de los derechos humanos en la agenda, cit., pp. 69 y ss.

13 Como las libertades de expresión e información, en su confluencia con las políticas de transparencia y rendición de cuentas. Ibidem, pp. 14 y ss. Para una introducción a las relaciones entre corrupción y transparencia véase M. CARBONELL, Transparencia, ética pública y combate a la corrupción. Una mirada constitucional, Instituto de Investigaciones Jurídicas de la Universidad Nacional Autónoma de México, México, 2009, en part. pp. 2, 5, 22. Para el tema específico de la rendición de cuentas, véase un diagnóstico del sistema mexicano en $\mathrm{M}$. MERINO et al., La estructura de la rendición de cuentas en México, Instituto de Investigaciones Jurídicas de la Universidad Nacional Autónoma de México, Centro de Investigación y Docencia Económicas, México, 2010, en part. pp. 19 y ss.

14 Véanse C. NASH et al., Corrupción y Derechos, cit., pp. 29-31; Id., “Derechos Humanos y Corrupción. Un enfoque multidimensional", cit., pp. 152-155.

15 La agenda de derechos humanos puede ser útil para reforzar la agenda anticorrupción a partir de enriquecer "tres principios que son centrales para las políticas tanto anticorrupción como de derechos humanos: (1) participación, (2) transparencia y acceso a la información y (3) rendición de cuentas". La integración de los derechos humanos en la agenda, cit., p. 1.

16 Informe final del Comité Asesor del Consejo de Derechos Humanos, cit., párr. 24.

17 El propósito del enfoque es complementar la perspectiva del derecho penal y aumentar las posibilidades de sanción, al transitar a la exigencia de responsabilidad de parte del Estado por actos de corrupción, mediante un cambio de enmarque interpretativo al derecho internacional de los derechos humanos. Cfr. A. PETERS, "Corrupción y derechos humanos", en C. TABLANTE y M. MORALES ANTONIAZZI (eds.), Impacto de la corrupción, cit., pp. 71, 72,76 .

DERECHOS Y LIBERTADES

ISSN: $1133-0937$

Número 44, Época II, enero 2021, pp. 237-275

DOI: https://doi.org/10.20318/dyl.2021.5855 
fortalecer la prevención y el combate penal del fenómeno ${ }^{18}$, particularmente, tratándose de la corrupción cometida por los grandes consorcios privados.

\section{EFECTOS DE LA CORRUPCIÓN EN LOS DERECHOS HUMANOS}

El punto de partida común de los escritos del enfoque basado en derechos humanos es la tesis de que la corrupción produce un efecto negativo ${ }^{19}$ en el goce y ejercicio de los derechos. Entre otras consecuencias, se señala que la corrupción afecta ${ }^{20}$, obstaculiza ${ }^{21}$, amenaza ${ }^{22}$, impide $^{23}$, destruye ${ }^{24} \mathrm{o}$ incluso viola ${ }^{25}$ los derechos humanos. Se afirma que esta relación negativa puede apreciarse intuitivamente ${ }^{26} \mathrm{o}$ ser evidente en la práctica ${ }^{27}$ al grado de

18 Véanse C. ROSE, "Limitations of a Human Rights Approach to Corruption, cit., pp. 405-438; K. E. DAVIS, "Corruption as a Violation of International Human Rights: A Reply to Anne Peters", The European Journal of International Law, vol. 29, núm. 4, 2018, pp. 1289-1296; F. PEIRONE, "Corruption as a Violation of International Human Rights: A Reply to Anne Peters", The European Journal of International Law, vol. 29, núm. 4, 2018, pp. 1297-1302.

19 Informe final del Comité Asesor del Consejo de Derechos Humanos, cit., párr. 19.

20 "[L]a corrupción [...] afecta a los derechos humanos en su integralidad -civiles, políticos, económicos, sociales, culturales y ambientales". Resolución 1/18 Corrupción y Derechos Humanos, cit.

21 "La corrupción constituye uno de los principales obstáculos a la promoción y protección efectivas de los derechos humanos". Observación general núm. 24 (2017) sobre las obligaciones de los Estados en virtud del Pacto Internacional de Derechos Económicos, Sociales y Culturales en el contexto de las actividades empresariales, E/C.12/GC/24, Comité de Derechos Económicos, Sociales y Culturales, párr. 20.

${ }_{22}$ "[L]a corrupción en todos los ámbitos amenaza al estado de derecho, la democracia y los derechos humanos". Informe final del Comité Asesor del Consejo de Derechos Humanos, cit., párr. 19.

23 "[L]a corrupción, ya sea sistémica, endémica o leve, impide a los ciudadanos disfrutar de todos los derechos recogidos en los instrumentos internacionales". La corrupción y sus repercusiones en el pleno disfrute de los derechos humanos, en particular los derechos económicos, sociales y culturales. Informe preliminar de la Relatora Especial, Sra. Christy Mbonu, cit., párr. 57.

24 "La corrupción [d]estruye los derechos básicos de miles de millones de personas". Declaración contra la corrupción, Transparencia Internacional.

25 "Desde esta perspectiva, a menudo se da por sentado que la corrupción "viola" los derechos humanos". Corruption and Human Rights: Making the Connection, cit., p. 23.

26 "[L]a relación entre corrupción y vulneración de derechos humanos puede resultar intuitivamente evidente (los derechos humanos tratan de limitar el poder y la corrupción es un abuso de poder)". R. MARTINÓN QUINTERO, “Corrupción y Derechos Humanos. En particular, la Corte Interamericana de Derechos Humanos", Eunomía. Revista en Cultura de la Legalidad, núm. 10, 2016, p. 8.

27 Corruption and Human Rights: Making the Connection, cit., p. 3.

ISSN: $1133-0937$

DOI: https://doi.org/10.20318/dyl.2021.5855
DERECHOS Y LIBERTADES

Número 44, Época II, enero 2021, pp. 237-275 
constituir una tautología ${ }^{28}$. También se le sustenta en evidencia anecdótica ${ }^{29}$ o empírica ${ }^{30}$, con señalamientos generales como la constatación de que los países con niveles más altos de corrupción (por ejemplo, en los índices de TI) presentan niveles bajos de respeto a los derechos ${ }^{31}$.

La identificación de este efecto negativo tiene como propósito poner énfasis en el daño que los actos de corrupción causan a la gente, dando un "rostro humano" 32 a la corrupción. Así, los escritos del enfoque se interesan por las víctimas ${ }^{33}$, las personas ordinarias que enfrentan cotidianamente la corrupción, en ocasiones como una experiencia inseparable de la violación a sus derechos ${ }^{34}$. Mientras las víctimas permanecen invisibles para el enfoque penal dominante sobre la corrupción, interesado principalmente en la responsabilidad de los autores individuales ${ }^{35}$, el enfoque de derechos humanos propone visibilizar a esas víctimas de actos corruptos, como una manera de empoderarlas ${ }^{36}$ y mejorar su estatus ${ }^{37}$. En este reposicionamiento de las víctimas, también se resalta que la corrupción afecta con mayor intensidad

28 "[L]a corrupción constituye entonces -en un sentido muy general- la negación de la idea de los derechos humanos. Por consiguiente, no solo existe un nexo, sino que casi hay una tautología". A. PETERS, "Corrupción y derechos humanos", cit., p. 28.

29 Mencionando casos en los que se hizo patente la afectación. Véase Z. PEARSON, "An international human rights to corruption", cit., pp. 52 y ss.

30 Véanse T. LANDMAN y C. J. W. SCHUDEL, Corruption and Human Rights: Empirical Relationships and Policy Advice, Working paper for the International Council on Human Rights Policy, 2007; A. N. ASTHANA, "Human Rights and Corruption: Evidence from a Natural Experiment", Journal of Human Rights, vol. 11, núm. 4, 2012, pp. 526-536; L. A. CARDONA ACUÑA, H. ORTÍZ RÍOS y L. D. VÁZQUEZ VALENCIA, "Corrupción y derechos humanos: de la intuición a la convicción", Revista Mexicana de Sociología, vol. 80, núm. 3, 2018, pp. 577610; L. A. CARDONA, H. ORTÍZ y D. VÁZQUEZ, "Corruption and Human Rights: Possible Relations", Human Rights Quarterly, vol. 40, núm. 2, 2018, pp. 317-341.

31 Véase Los derechos humanos y la corrupción, Transparencia Internacional, cit., p. 1; A. PETERS, "Corrupción y derechos humanos", cit., pp. 24-25. PEIRONE cuestiona la validez de estas observaciones, mencionando países en los que la correlación no se cumple. F. PEIRONE, "Corruption as a Violation of International Human Rights: A Reply to Anne Peters", cit., pp. 1297-1302.

32 Z. PEARSON, “An international human rights approach to corruption", cit., p. 59.

33 Informe final del Comité Asesor del Consejo de Derechos Humanos, cit., párr. 27.

34 Cfr. M. K. ANDERSEN, "Why Corruption Matters in Human Rights", Journal of Human Rights Practice, vol. 10, 2018, pp. 179-190.

35 Informe final del Comité Asesor del Consejo de Derechos Humanos, cit., párr. 25; C. ROSE, "Limitations of a Human Rights Approach to Corruption", cit., p. 11.

36 Cfr. C. R. KUMAR, Corruption and Human Rights in India: Comparative Perspectives on Transparency and Good Governance, Oxford University Press, Nueva Delhi, 2014, pp. 9-10, 43.

37 A. PETERS, “Corrupción y derechos humanos”, cit., p. 69.

DERECHOS Y LIBERTADES

Número 44, Época II, enero 2021, pp. 237-275
ISSN: 1133-0937

DOI: https://doi.org/10.20318/dyl.2021.5855 
a los pobres y a los miembros de grupos vulnerables como mujeres, niños e indígenas ${ }^{38}$.

Ahora bien, intuitivamente parece que ese daño no es el mismo en todos los casos. En el universo de los actos ilícitos considerados corruptos, se identifican algunos en los cuales la lesión a las personas es inmediata y visible; sin embargo, también hay otros en los cuales ese daño no es claro o parece no existir, al no haber víctimas identificables. Podría incluso pensarse en actos de corrupción que no tengan efectos en los derechos de ninguna persona. En este punto, el enfoque basado en derechos se aleja de esta idea intuitiva. La segunda tesis que se desprende de estos trabajos ${ }^{39}$ es la afirmación de que todos los actos de corrupción impactan negativamente en los derechos humanos, así sea remotamente ${ }^{40} \mathrm{o}$ en el largo plazo $^{41}$. De este modo, la relación negativa entre corrupción y afectación a derechos se sugiere de naturaleza necesaria.

Se puede debatir esta tesis, reiterando que la conexión entre corrupción y violaciones de derechos humanos no se presenta en todos los $\operatorname{casos}^{42}$, o sosteniendo que tiene una "naturaleza indeterminada": en algunos casos es imposible negar que la corrupción es causa directa de una disminución en el disfrute de algún derecho específico, pero en otros, en los que la afectación es indirecta, la conexión tiene que entenderse como "contingente" 43. Igualmente, desde la perspectiva empírica, se señala que más allá de los casos anecdóticos, no hay evidencia suficiente sobre esta correlación negativa

38 Cfr. J. T. GATHII, "Defining the relationship between Human Rights and Corruption", University of Pennsylvania Journal of International Law, vol. 31, núm. 1, 2009, pp. 125-202; Corruption and Human Rights: Making the Connection, cit., pp. 7-10; Resolución 1/18 Corrupción y Derechos Humanos, cit.

39 Tesis sostenida explícitamente por los reportes del ICHRP y sugerida por el lenguaje en los otros trabajos y documentos aquí citados, que hablan de las consecuencias negativas de la corrupción en general, y no de ciertos tipos o modalidades de corrupción.

40 La integración de los derechos humanos en la agenda, cit., p. vii.

41 J. BACIO-TERRACINO, Corruption as a Violation of Human Rights, Working paper for the International Council on Human Rights Policy, 2008, pp. 1, 10.

42 Dice MALEM SEÑA: "La conexión entre determinadas formas de corrupción y la violación de los derechos humanos no resulta difícil de establecer bajo la condición de que se acepte que no todo acto de corrupción afecta los derechos humanos. La vinculación de los derechos humanos a casi cualquier actividad humana es un defecto teórico y una inadecuación pragmática que hay que evitar". J. F. MALEM SEÑA, "Derechos humanos y corrupción", Crítica, núm. 989, 2014, pp. 48-51.

43 K. E. DAVIS, “Corruption as a Violation of International Human Rights: A Reply to Anne Peters", cit., pp. 1289-1291. 
entre corrupción y violaciones de derechos humanos ${ }^{44}$, que pruebe que las afectaciones se presentan ya no se diga en todos los casos, sino al menos de manera generalizada ${ }^{45}$.

Estas objeciones solo pueden hacerse a un lado si la naturaleza necesaria de la afectación a derechos humanos por la corrupción se afirma por una razón conceptual ${ }^{46}$, con independencia de la relación causa-efecto. Sin embargo, los escritos del enfoque escasamente profundizan en esta conexión conceptual $^{47}$. En sustitución, eludiendo de cierta manera este problema, los estudios más minuciosos ofrecen una categorización de afectaciones, que cataloga los actos de corrupción en función de su grado de impacto en los derechos. El efecto negativo se da por sentado, pero se reconoce que es muy distinto decir que un acto de corrupción amenaza un derecho, a decir que lo viola.

Particularmente, los estudios del ICHRP se preocupan por establecer diversos criterios para esta clasificación, según se dice, para evitar el "abuso" y la "banalización" de la aplicación "sensible" de los principios de derechos humanos ${ }^{48}$. Igualmente, para los efectos jurídicos de defensa de los derechos que propone, Peters considera fundamental distinguir un acto que solo afecta remotamente los derechos de una "verdadera violación" 49 a estos.

La categorización es casuística y tiene en cuenta, fundamentalmente, la existencia o no de un vínculo causal apreciable prácticamente. Con algunas variaciones, en los análisis se delinean las siguientes categorías:

44 Cfr. F. PEIRONE, "Corruption as a Violation of International Human Rights: A Reply to Anne Peters", cit., pp. 1297, 1299.

45 El sentido de la "evidencia empírica" aportada puede no ser útil para probar esta relación, pues no dice nada sobre la dirección de la relación ni sobre la influencia de otros factores. Por ejemplo, en un estudio realizado en México, se correlaciona estadísticamente el número de homicidios (como indicador de los derechos civiles), con el número de observaciones emitidas por el órgano encargado de fiscalizar la cuenta pública (como indicador de la corrupción). Entre las conclusiones, se apunta que, en un determinado lugar y tiempo, a mayor gravedad de esas observaciones sobre el presupuesto, más número de homicidios. Es difícil interpretar esto más que como una coincidencia interesante. Cfr. L. A. CARDONA, H. ORTÍZ y L. D. VÁZQUEZ, "Violación de derechos humanos en México: Un costo poco advertido de la corrupción”, Política y gobierno, vol. XXV, núm. 1, 2018, pp. 153-184.

46 Véase infra Apartado 4.

47 Cfr. C. ROSE, “Limitations of a Human Rights Approach to Corruption”, cit., p. 409.

48 Corruption and Human Rights: Making the Connection, cit., p. 4.

49 A. PETERS, “Corrupción y derechos humanos”, cit., p. 36. 
A) Actos de corrupción que afectan de manera remota derechos humanos.

En estos casos no se puede establecer en la práctica el vínculo causal que conduce del acto corrupto a la violación concreta de un derecho ${ }^{50}$. La relación es distante y débil, pues la corrupción es solo uno entre otros muchos factores que podrían conducir a la lesión del derecho.

Aunque no se puede establecer en la práctica, el vínculo se tiene por existente de forma hipotética (por la conexión necesaria que se postula, comentada antes). La afirmación de esta relación tiene fines meramente retóricos, pues supone reconocer las consecuencias dañosas que tiene la corrupción en abstracto, haciendo uso de un "vocabulario débil" ${ }^{1}$, sin que esto tenga implicaciones analíticas ni repercusiones jurídicas.

En esta indeterminación, se puede llegar a afirmar que, así como todo acto de corrupción afecta derechos humanos, igualmente "casi cualquier derecho humano puede verse afectado por la corrupción" 52 .

B) Actos de corrupción que son causa indirecta de afectaciones a derechos humanos.

En estos casos sí se establece un vínculo de causalidad entre el acto corrupto y la violación de un derecho, pero esta relación no es directa ni inmediata. La práctica corrupta es una "condición necesaria" y un "factor esencial" que contribuye en una "cadena de acontecimientos" que conducen al acto violatorio del derecho ${ }^{53}$, pero el acto corrupto y el que determina la violación son diversos. El acto de corrupción, en sí mismo, no viola el derecho, pero es un antecedente que genera un riesgo directo ${ }^{54}$, siendo requerido para que la violación se produzca.

C) Actos de corrupción que constituyen violaciones directas de derechos humanos.

En estos casos sí existe un vínculo causal directo, que se da cuando el acto de corrupción es usado deliberadamente como un medio para violar el

50 Corruption and Human Rights: Making the Connection, cit., pp. 24, 28.

51 A. PETERS, "Corrupción y derechos humanos", cit., p. 33.

52 Informe final del Comité Asesor del Consejo de Derechos Humanos, cit., párr. 18.

53 Corruption and Human Rights: Making the Connection, cit., p. 27. pp. $143,145$.

54 C. NASH, "Derechos Humanos y Corrupción. Un enfoque multidimensional", cit., 
derecho, o cuando el acto de corrupción impide a una persona tener acceso al derecho ${ }^{55}$. En este segundo renglón, el vínculo también se presenta cuando el impedimento es resultado de una omisión del Estado ${ }^{56}$.

A partir de la existencia de ese vínculo causal directo, se establece una causalidad jurídica cuando el acto de corrupción constituye, a su vez, un incumplimiento de alguna de las obligaciones del Estado ${ }^{57}$ en materia de derechos humanos establecidas por el derecho internacional ${ }^{58}$. Adicionalmente, para determinar esta causalidad jurídica importa tener en cuenta otros elementos como la "previsibilidad" de la violación del derecho, y que la realización de la lesión no está "muy distante" del funcionario público responsable del acto corrupto ${ }^{59}$.

Peters remarca que esta identificación jurídica entre el acto de corrupción y el incumplimiento sancionable de una obligación estatal en materia de derechos es imprescindible para ir más allá de la "idea vaga" del "vínculo", y pasar a la afirmación de que el acto corrupto (o la tolerancia de este) "viola" un derecho en el sentido jurídico ${ }^{60}$. Solo cuando este análisis técnico detallado muestra a la corrupción como un incumplimiento de obligaciones del estado, existiría base legal para un eventual reclamo de responsabilidad del Estado por la violación del derecho, en el marco del derecho internacional de los derechos humanos.

55 Corruption and Human Rights: Making the Connection, cit., p. 27; J. BACIOTERRACINO, Corruption as a Violation, cit., pp. 10-11.

56 Informe final del Comité Asesor del Consejo de Derechos Humanos, cit., párr. 29.

57 Los estándares internacionales sobre las obligaciones del Estado en materia de derechos humanos no son uniformes. De acuerdo con el Comité de Derechos Económicos, Sociales y Culturales, las obligaciones son tres: obligación de respetar, de proteger y de cumplir. El Comité de Derechos Humanos y la Corte Interamericana de Derechos Humanos coinciden en identificar dos obligaciones centrales: respetar, y garantizar y adoptar medidas. Véase S. SERRANO, "Obligaciones del Estado frente a los derechos humanos y sus principios rectores: una relación para la interpretación y aplicación de los derechos", en E. FERRER MACGREGOR et al. (coords.), Derechos humanos en la Constitución. Comentarios de jurisprudencia constitucional e interamericana, Suprema Corte de Justicia de la Nación, Instituto de Investigaciones Jurídicas de la Universidad Nacional Autónoma de México, Fundación Konrad Adenauer, México, 2013, pp. 89-132.

58 Cfr. A. PETERS, "Corrupción y derechos humanos", cit., pp. 36 y ss; R. HEMSLEY, "Human Rights \& Corruption: States' Human Rights Obligation to fight Corruption", Journal of Transnational Legal Issues, vol. 2, núm. 1, 2015, pp. 1-24.

59 A. PETERS, "Corrupción y derechos humanos", cit., pp. 51 y ss.

60 Cfr. Id., "Corruption as a Violation of International Human Rights”, cit., p. 1253.

DERECHOS Y LIBERTADES

ISSN: 1133-0937

Número 44, Época II, enero 2021, pp. 237-275

DOI: https://doi.org/10.20318/dyl.2021.5855 
D) Actos generalizados de corrupción que afectan de manera generalizada los derechos humanos.

En una cuarta categoría, se consideran los casos en los cuales las afectaciones y violaciones -indistintamente- de derechos son consecuencia de "contextos" ${ }^{61}$ de corrupción sistémica. En estos escenarios, la corrupción no solo afecta derechos humanos en casos individuales, sino que, debido a su proliferación, se convierte en "un obstáculo estructural" ${ }^{2}$ para el disfrute de los derechos.

En estas situaciones críticas de altos niveles de corrupción, sencillamente el Estado cooptado es incapaz de cumplir con las obligaciones relacionadas con los derechos ${ }^{63}$, con lo cual las personas están en riesgo constante de sufrir menoscabo en sus derechos. En estas sociedades, las oportunidades solo están aseguradas por la lealtad a la élite y la impunidad es la regla, por lo cual la corrupción se experimenta no sólo como una falla del imperio de la ley, sino como un efecto del régimen político ${ }^{64}$.

Ahora bien, un Estado resulta responsable de esa situación constante de afectaciones o violaciones de derechos por omisión: por tolerar, con su inacción, la proliferación de la corrupción hasta esos niveles. Esta inacción se presenta cuando no se ha cumplido la obligación de implementar en forma efectiva las medidas anticorrupción, tanto para prevenir esa situación extrema, como para corregirla cuando ya existe. La falta de esas medidas anticorrupción ${ }^{65}$ supone a su vez un incumplimiento de las obligaciones internacionales del Estado en materia de derechos humanos ${ }^{66}$, resultando por tanto en una violación ${ }^{67}$.

61 C. NASH, "Derechos Humanos y Corrupción. Un enfoque multidimensional”, cit., pp. $143,146$.

62 Id. et al., Corrupción y Derechos, cit., p. 26.

63 J. T. GATHII, "Defining the relationship between Human Rights and Corruption”, cit., p. 147; Corruption and Human Rights: Making the Connection, cit., p. 23.

64 Cfr. M. K. ANDERSEN, “Why Corruption Matters, cit., p. 185.

65 Medidas de prevención establecidas en la Convención de Naciones Unidas, en el Capítulo II; y de criminalización y persecución penal en el Capítulo III.

66 Cfr. R. HEMSLEY, "Human Rights \& Corruption: States' Human Rights Obligation to fight Corruption”, cit., pp. 1-24. También sobre las obligaciones estatales de prevenir y combatir la corrupción en el marco del "orden público internacional", véase J. A BURNEO LABRÍN, "Corrupción y Derecho Internacional de los derechos humanos", Revista de Derecho PUCP, núm. 63, 2009, pp. 333-347.

67 Cfr. A. PETERS, "Corruption as a Violation of International Human Rights", cit., pp. 1258-1260. 
Como se observa, solo los casos de corrupción que se inscriben en los incisos B) y C) se califican en un sentido jurídico técnico como violaciones de derechos, cometidas ya sea de forma directa o indirecta. Como ya se mencionó, los dos puntos fundamentales para afirmar la existencia de la violación son el vínculo causal entre el acto de corrupción y el resultado lesivo, así como la identificación jurídica entre el acto de corrupción y el incumplimiento de una obligación estatal en materia de derechos.

Establecida esta distinción analítica, los estudios comentados se interesan por hacer listados de los derechos humanos que "regularmente" 68 son violados por la corrupción, ilustrando las formas como se producen esas lesiones ${ }^{69}$. Los derechos económicos y sociales como la salud ${ }^{70}$ y la educación ${ }^{71}$ son mencionados como particularmente vulnerables, porque su realización está sujeta a la disponibilidad de recursos públicos destinados a la prestación de servicios. Esos recursos son susceptibles de ser desviados a fines privados por la corrupción ${ }^{72}$, lo que incumple el principio de progresividad $^{73}$.

También se menciona el derecho a la igualdad que prácticamente se considera afectado en todo caso, cuando un acto de corrupción significa dar un trato privilegiado a un sujeto al margen de la igualdad legal, lo que se traduce en discriminación ${ }^{74}$. Las listas tienden a extenderse, bajo la idea de que "[e]s difícil encontrar un derecho humano que no pueda resultar vulnerado por la corrupción" 75 .

68 Corruption and Human Rights: Making the Connection, cit., p. 31.

69 J. BACIO-TERRACINO, Corruption as a Violation, cit., pp. 11 y ss.; C. NASH, "Derechos Humanos y Corrupción. Un enfoque multidimensional", cit., pp. 143, 146.

70 Véase B. TOEBES, "Chapter V. Health Sector Corruption and Human Rights: a Case Study”, en M. BOERSMA y H. NELEN (eds.), Corruption \& Human Rights, cit., pp. 91-123.

${ }_{71}$ Véanse M. BOERSMA, "Chapter IV. Corruption as a Violation of Economic, Social and Cultural Rights: Reflections on the Right to Education", en M. BOERSMA y H. NELEN (eds.), Corruption $\mathcal{E}$ Human Rights, cit., pp. 51-89; A. PETERS, "Corruption as a Violation of International Human Rights", cit., p. 1256.

72 Observación general núm. 24 (2017) sobre las obligaciones de los Estados, cit., párr. 20; Resolución 1/18 Corrupción y Derechos Humanos, cit., resolutivo 3; Los derechos humanos y la corrupción, Transparencia Internacional, cit., p. 3.

73 M. MORALES ANTONIAZZI, “Aproximación a los estándares, cit., p. 349.

74 Cfr. J. BACIO-TERRACINO, Corruption as a Violation, cit., pp. 33-36; Corruption and Human Rights: Making the Connection, cit., pp. 32 y ss.

75 Informe final del Comité Asesor del Consejo de Derechos Humanos, cit., párr. 17.

DERECHOS Y LIBERTADES

Número 44, Época II, enero 2021, pp. 237-275
ISSN: $1133-0937$

DOI: https://doi.org/10.20318/dyl.2021.5855 


\section{REDEFINICIÓN DE LA CORRUPCIÓN A PARTIR DE SU RELACIÓN CON LOS DERECHOS HUMANOS}

En el terreno conceptual, la mayor parte de los escritos de este enfoque reconocen la falta de una definición única de corrupción y optan por tomar como base las nociones más usuales ${ }^{76}$, sin profundizar en la tarea de revisar el concepto a la luz de su vínculo con los derechos humanos. En el sentido jurídico, se reitera que la corrupción se entiende como la tipología de conductas ilegales previstas en los tratados como la Convención de Naciones Unidas contra la Corrupción [CNUCC] y otros documentos internacionales ${ }^{77}$ que, en efecto, enlistan los actos ilegales, pero no definen el fenómeno. Al mismo tiempo, se sostiene expresamente que, para el análisis de las consecuencias negativas de la corrupción, no es "absolutamente necesario elaborar una definición precisa de corrupción" 78 .

El problema conceptual supone ir un paso más allá en el establecimiento del vínculo entre derechos humanos y corrupción. Más que dilucidar en qué casos un acto de corrupción causa una violación a un derecho humano, la pre-

76 Por ejemplo, se refieren las definiciones del Banco Mundial y de TI (corrupción como abuso de poder encomendado para la obtención de beneficio propio); o de R. KLITGAARD (corrupción como la ecuación: Corrupción = Poder monopólico + Discreción - Rendición de cuentas). Véanse Z. PEARSON, "An international human rights approach to corruption”, cit., pp. 32-33; Corruption and Human Rights: Making the Connection, cit., pp. 15-18; J. HATCHARD, "Chapter II. Adopting a human rights approach towards combating corruption", en M. BOERSMA y H. NELEN (eds.), Corruption \& Human Rights, cit., pp. 7-23; C. NASH et al., Corrupción y Derechos, cit., pp. 16-21. Como parte del abuso de poder, la corrupción implica una desviación de deberes formales o la violación de reglas para favorecer un interés privado. Cfr. L. PELLEGRINI, Corruption, Development and the Environment, cit., pp. 16-17.

77 La Convención de Naciones Unidas señala como actos criminalizables los siguientes: Soborno de funcionarios públicos nacionales (artículo 15); Soborno de funcionarios públicos extranjeros y de funcionarios de organizaciones internacionales públicas (artículo 16); Malversación o peculado, apropiación indebida u otras formas de desviación de bienes por un funcionario público (artículo 17); Tráfico de influencias (artículo 18); Abuso de funciones (artículo 19); Enriquecimiento ilícito (artículo 20); Soborno en el sector privado (artículo 21); Malversación o peculado de bienes en el sector privado (artículo 22); Blanqueo del producto del delito (artículo 23); Encubrimiento (artículo 24); Obstrucción de la justicia (artículo 25). Convención de las Naciones Unidas contra la Corrupción, cit. Para listados similares véanse Convención Interamericana contra la Corrupción, Organización de Estados Americanos, 29 marzo 1999, artículo VI; Convención de la Unión Africana para Prevenir y Combatir la Corrupción, Asamblea de la Unión, 11 julio 2003, artículo 4; Convenio Penal sobre sobre la Corrupción (Convenio núm. 173 del Consejo de Europa), Estrasburgo, 27 enero 1999, artículos 2-14.

Informe final del Comité Asesor del Consejo de Derechos Humanos, cit., párr. 6.

ISSN: 1133-0937

DOI: https://doi.org/10.20318/dyl.2021.5855
DERECHOS Y LIBERTADES

Número 44, Época II, enero 2021, pp. 237-275 
gunta es si la corrupción por sí misma es una violación a derechos humanos. Se trata de dos discusiones paralelas, que Spalding identifica como dos perspectivas dentro de este enfoque de estudios: la perspectiva "causa-efecto", que aborda la corrupción como un "medio" para violar derechos; y la perspectiva que considera a la corrupción como una violación "inherente" de derechos ${ }^{79}$.

Peters plantea una cuestión cercana en sus propios términos: distingue el "análisis doctrinal del derecho positivo", que permite determinar cuándo un acto de corrupción se califica legalmente como violatorio de derechos ${ }^{80}$, de la "valoración normativa", que aborda el problema sobre si la corrupción "debe" conceptualizarse como una violación de derechos humanos, y si esto ofrece algún valor agregado en términos prácticos o de política. En su posición, una vez que ha identificado que un acto de corrupción sí puede calificarse legalmente como una violación de derechos en ciertos casos, concluye considerando que también "debe" considerarse como una "potencial" violación de derechos humanos, porque esta calificación puede ser útil para reforzar la implementación de los tratados anticorrupción, complementando la definición del enfoque penal. Esta autora reconoce que la valoración normativa es "ambivalente" pues plantea múltiples dificultades teóricas; de ahí que, si se inclina por una respuesta positiva, lo hace "con toda cautela", en tanto ofrece "beneficios prácticos" para la lucha anticorrupción ${ }^{81}$.

La respuesta de Peters a la cuestión normativa que plantea no es contundente $^{82}$. Para lo que aquí interesa, además de sus razones utilitaristas, se requieren otras razones sustanciales para sostener la reconceptualización de la corrupción como una violación de derechos. Es decir, se requiere mostrar que la corrupción se conecta con los valores protegidos por el régimen del derecho internacional de los derechos humanos, en una dimensión distinta de la empírica (eventual relación de causa-efecto) y de la jurídica (determinación legal de violación de derecho o no).

Según se desprenden de los estudios del enfoque, estas razones se aportan desde tres argumentos: el argumento de la corrupción generalizada, el argumento de la libertad y el argumento del derecho al desarrollo.

79 Cfr. A. B. SPALDING, "Corruption, Corporations, and the New Human Right", Washington University Law Review, vol. 91, núm. 6, 2014, pp. 1365-1428.

${ }_{80}$ Véase supra Apartado $3 \mathrm{C}$ ).

81 Cfr. A. PETERS, “Corruption as a Violation of International Human Rights”, cit., pp. $1253,1286-1287$.

82 Cfr. F. PEIRONE, "Corruption as a Violation of International Human Rights: A Reply to Anne Peters”, cit., pp. 1297, 1299. 
Véase el primer argumento. De los estudios comentados, precisamente a partir de la insistencia en los efectos negativos de la corrupción, se desprende una consideración implícita de que la corrupción puede redefinirse como una violación de derechos, cuando se ha extendido en grado sumo dentro de una sociedad ${ }^{83}$. En este planteamiento, independientemente de si un acto de corrupción es un delito o repercute en violaciones a un derecho concreto, se insinúa que la corrupción en ese grado generalizado, por su condición de ser opuesta a los derechos humanos, es en sí misma violatoria de estos ${ }^{84}$.

La corrupción está ampliamente extendida dentro de una sociedad cuando se presenta en todos los niveles jerárquicos del gobierno, tanto en la burocracia baja como en las altas esferas de la política ${ }^{85}$; igualmente, cuando se presenta en las diversas áreas: administrativa, judicial e incluso legislativa. La extensión no es solo una cuestión numérica, sino sistémica; como describe Arellano, esto se presenta cuando las prácticas corruptas son la "costumbre", se "autorreproducen" al estar integradas en un "entramado" de "relaciones sociales" en el que están involucrados tanto la estructura gubernamental como las empresas y otros agentes privados. La corrupción sistémica es una "trampa social", pues no es fácil para los actores "salirse del acuerdo" que normaliza los actos de corrupción ${ }^{86}$.

Si se lleva ese escenario de corrupción sistémica a un extremo hipotético, se puede imaginar una situación en la cual todos y cada uno de los actos de autoridad y de las interacciones entre los agentes del Estado y los ciudadanos están viciados por la corrupción. En esa sociedad, el Estado simplemente abandona la obligación de garantizar el disfrute de los derechos, y se con-

83 Véase supra Apartado 3 D).

84 Por ejemplo, se apunta que, en los escenarios de corrupción en grado sistémico, la corrupción es causa de violaciones a derechos humanos, pero también es "una violación por y en sí misma". Los derechos humanos son el "constitutivo opuesto" de una sociedad corrupta. Cfr. M. K. ANDERSEN, “Why Corruption Matters, cit., p. 185.

85 De acuerdo con la conocida distinción entre grand corruption (cometida por altos funcionarios en el otorgamiento de contratos a gran escala) y petty corruption (cometida por funcionarios de bajo nivel en el cobro por servicios al ciudadano). Cfr. S. ROSE-ACKERMAN \& R. TRUEX, Corruption and Policy Reform, Working Paper Prepared for the Copenhagen Consensus Project, 2012.

86 Cfr. D. ARELLANO GAULT, “Corrupción ¿calle de una sola vía? La internalización del soborno en empresas en México", Iztapalapa. Revista de Ciencias Sociales y Humanidades, núm. 84, 2018, pp. 163-190; Id., "Corrupción como proceso organizacional: comprendiendo la lógica de la desnormalización de la corrupción”, Contaduría y Administración, núm. 62, 2017, pp. 810-826. 
vierte en una maquinaria de abuso de poder. Un Estado así no es otra cosa que una "banda de corruptos", que detentan el poder e imponen su ley para su propio beneficio.

En este plano, la corrupción generalizada se opone a los derechos humanos porque, de imperar en la sociedad, supondría la existencia de un modelo estatal contrario al modelo de Estado constitucional de derecho justificado normativamente por estar basado en el valor de la dignidad humana. En ese escenario teórico la corrupción se vuelve por sí misma violatoria de derechos porque excluye completamente la posibilidad de los derechos, al convertir el gobierno en un medio para la obtención de beneficios privados a costa de los demás.

Esta consideración teórica es distinta de la cuestión empírica. No se trata de saber cuánta corrupción ha de presentarse en una sociedad concreta, para comprobar si se ha alcanzado o no ese punto extremo de negación de los derechos. Más bien, lo que se plantea es una oposición entre modelos de Estado: uno que tutela la dignidad, y otro que la socava. Aquí, este argumento se conecta con la cuestión de la legitimidad estatal. Un modelo de Estado corrompido, que excluye el respeto de la dignidad, es ilegítimo desde lo que Rajagopal identifica como el "modelo de legitimidad de los derechos". En esta idea, la corrupción y los derechos humanos son las "dos caras contrarias de la misma moneda": una deslegitima al Estado, los otros son el criterio contemporáneo para medir esa legitimidad ${ }^{87}$.

Este argumento implica una visión "moralizante" de la corrupción, en la cual se asume como un mal que resulta moralmente repudiable en todos los $\operatorname{casos}^{88}$. Como apunta Garzón Valdés, la corrupción es una práctica que, en los sistemas democráticos y en el marco del Estado social de derecho, "es insalvablemente inmoral"; la palabra misma "tiene la connotación negativa de destrucción de algo que se considera valioso" ${ }^{89}$. Desde esta idea, se encuentra que aquello que la corrupción contamina o hace pútrido es el valor de la dignidad humana ${ }^{90}$ como base de toda organización jurídico-política.

87 Cfr. B. RAJAGOPAL, "Corruption, Legitimacy and Human Rights: The Dialectic of the Relationship", Connecticut Journal of International Law, vol. 14, núm. 2, 1999, pp. 495-507.

88 "[C]ondenamos la corrupción como inmoral, injusta y repugnante para los ideales de humanidad consagrados en la Declaración Universal de Derechos Humanos". The Seoul Findings, 11th International Anti-Corruption Conference. Seoul, 2003.

89 E. GARZÓN VALDÉS, “Acerca de la calificación moral de la corrupción. Tan sólo una propuesta", Isonomía, núm. 21, 2004, pp. 9-19.

${ }_{90}$ El ICHRP refiere que algunos académicos sostienen que "la corrupción endémica destruye los valores fundamentales de la dignidad humana y la igualdad política". Corruption 
La corrupción viola por sí misma los derechos humanos porque, con su proliferación, emponzoña el fundamento normativo del Estado.

El segundo argumento atiende también a los fundamentos del Estado, aunque desde la óptica de la filosofía política liberal clásica. En particular, Spalding sostiene que la corrupción viola el "derecho natural a la libertad", a partir de una relectura de la teoría de Locke sobre la libertad y el fundamento del Estado civil. En esta relectura, la corrupción se identifica con la "tiranía", que Locke describe como el uso del poder detentado no para el bien de aquellos que están sujetos a ese poder, sino para la propia ventaja privada. Para explicitar esa identificación, Spalding propone definir a la corrupción como "la conducta de un actor público o privado que procura la obtención de algún beneficio ya sea personal o para otros, en contravención de un deber oficial o fiduciario y de los derechos de otros" ${ }^{91}$.

Según reseña Spalding, en el ideario de Locke, cuando el gobierno se rige por las leyes promulgadas por el pueblo para el beneficio común, el derecho natural a la libertad se "protege" y se "disfruta". La libertad, dentro de la sociedad civil, es vivir bajo "el gobierno de las reglas", dadas por el legislativo para todos, sin estar sujeto a la "voluntad" "arbitraria" de otro hombre. Para Spalding, esta libertad de Locke solo existe cuando el "gobierno confiere beneficios de acuerdo con el deber oficial de gobernar según las leyes dirigidas al bien común"; por tanto, esta libertad es violada cuando los funcionarios conceden beneficios incumpliendo ese deber, sea para sí mismos o para otros, como sucede con la corrupción. Dado que la corrupción viola este derecho natural de libertad, al avasallarlo para el beneficio privado de quien gobierna, este autor considera que "la corrupción anula el contrato social, destruye el gobierno y regresa a la sociedad al estado de naturaleza". Además de violar la libertad, la corrupción "es la fuente de la que surgen otras muchas violaciones" 92.

Así, en este liberalismo revisitado, la corrupción resulta ser una "violación inherente" de la libertad, porque la subordina a un régimen político que persigue el beneficio privado. Este argumento tiene también una relación clara con la idea de legitimidad: el gobierno de tiranía-corrupción resulta ilegítimo, porque no persigue el cumplimiento de la libertad en el marco del gobierno de las leyes.

and Human Rights: Making the Connection, cit., p. 3.

91 A. B. SPALDING, "Corruption, Corporations, and the New Human Right", cit., pp. 1395-1398.

92 Ibidem, pp. 1368, 1397-1398. 
El tercer argumento sostiene que la corrupción es una violación del derecho humano al desarrollo. El fundamento de este argumento deriva de la idea generalizada dentro de las políticas anticorrupción, de que los altos niveles de corrupción impiden el éxito de las acciones para el desarrollo, tanto en el aspecto económico como social ${ }^{93}$. La relación negativa entre corrupción y desarrollo se plantea incluso en el Preámbulo de la CNUCC, que señala que la corrupción "compromet[e] el desarrollo sostenible" 94 . En cierta lectura, esta noción de "desarrollo sostenible" implica a los derechos económicos y sociales, cuya satisfacción se ve también comprometida por la corrupción ${ }^{95}$.

De este modo, si la corrupción es un "fuerte factor que inhibe" 96 o interfiere $^{97}$ con el desarrollo, en un grado tal que llega a nulificar los esfuerzos realizados para conseguirlo, resulta ser por sí misma una violación del derecho al desarrollo reconocido por Naciones Unidas desde $1986^{98}$. La fuerza de esta afirmación radica en que, a diferencia de las violaciones a otros derechos

93 El Banco Mundial colocó el tema de la corrupción en el centro de las políticas sobre desarrollo, lo que se hizo consenso a mediados de los noventa. Desde entonces, la corrupción se entiende como un impedimento mayor para el éxito de las reformas económicas; en un Estado corrupto, el desarrollo sostenible, tanto social como económico, se vuelve imposible. J. T. GATHII, "Defining the relationship between Human Rights and Corruption", cit., pp. 127, 144. Igualmente, se señala que la corrupción "hoy se reconoce como uno de los mayores obstáculos para el desarrollo". La integración de los derechos humanos en la agenda, cit., p. vii. En el mismo sentido, se sostiene que la corrupción tiene efectos negativos en dos componentes fundamentales del desarrollo sostenible: el crecimiento económico y la protección ambiental. Cfr. L. PELLEGRINI, Corruption, Development and the Environment, cit., pp. 149 y ss.

94 "La Asamblea General [...] Preocupada por la gravedad de los problemas y las amenazas que plantea la corrupción para la estabilidad y seguridad de las sociedades al socavar las instituciones y los valores de la democracia, la ética y la justicia y al comprometer el desarrollo sostenible y el imperio de la ley". Convención de las Naciones Unidas contra la Corrupción, cit., Preámbulo.

95 Si se entiende "desarrollo sostenible" como la provisión de las necesidades de la generación presente, sin comprometer la habilidad de las generaciones futuras para satisfacer sus propias necesidades (de acuerdo con la visión del Informe Brundtland de 1987). The impact of corruption on the human rights based approach, cit., p. 26.

96 C. R. KUMAR, Corruption and Human Rights in India: Comparative Perspectives on Transparency and Good Governance, cit., p. 54.

97 The impact of corruption on the human rights based approach, cit., p. 7.

98 "El derecho al desarrollo es un derecho humano inalienable en virtud del cual todo ser humano y todos los pueblos están facultados para participar en un desarrollo económico, social, cultural y político en el que puedan realizarse plenamente todos los derechos humanos y libertades fundamentales, a contribuir a ese desarrollo y a disfrutar de él". Declaración sobre el Derecho al Desarrollo. Resolución 41/128, Asamblea General de la Organización de las Naciones Unidas, 4 diciembre 1986, Artículo 1.1. 
por actos de corrupción que se plantean de manera casuística, la violación del derecho al desarrollo por la corrupción se formula en un sentido general, aprovechándose del reconocimiento generalizado de la existencia de una correlación negativa entre altos niveles de corrupción y desarrollo económico y humano ${ }^{99}$. Si la corrupción viola el derecho al desarrollo al impedirlo, provoca el mismo daño a los derechos cuyo goce es inseparable del desarrollo, declarados por Naciones Unidas dentro de los Objetivos de Desarrollo del Milenio en el 2000, y de los Objetivos de Desarrollo Sustentable en 2012.

En sentido similar, Kofele-Kale encuentra que la corrupción viola el derecho colectivo al desarrollo, que en la dimensión económica permite a un país garantizar los derechos económicos y sociales, y en la dimensión social es esencial para que los individuos conozcan, exijan y disfruten sus derechos. Este ideal de desarrollo se vincula con el derecho a la autodeterminación económica -estipulado en los dos Pactos Internacionales de Derechos- que, de acuerdo con este autor, se viola por la corrupción cuando la riqueza nacional, que es el patrimonio del pueblo, en lugar de destinarse para el desarrollo, es objeto de apropiación por los poderosos o se enajena por el Estado en concesiones extranjeras. Así, la violación de este derecho por el Estado ocurre cuando se niega al pueblo, tanto en lo individual como en lo colectivo, el derecho a usar y disponer de la riqueza nacional de modo que contribuya para su desarrollo ${ }^{100}$.

Para cerrar este apartado, hay que destacar que los tres argumentos comentados se basan en un grupo de ideas y lugares comunes sobre la legitimidad y la justificación normativa del orden jurídico-político. En su conjunto, coinciden en ver a la corrupción como la negación del Estado constitucional

99 De acuerdo con abundante evidencia formulada desde el enfoque de los estudios económicos de la corrupción. Se sabe, por ejemplo, que la corrupción provoca "efectos paralizantes en el desarrollo humano y el bienestar", y que en general, "los países con altos niveles de corrupción tienen bajos niveles de desarrollo humano". S. ROSE-ACKERMAN \& R. TRUEX, Corruption and Policy, cit. Igualmente, se sostiene que la correlación entre el nivel de corrupción y el crecimiento está firmemente establecida, siendo claro que un alto nivel de corrupción tiene un impacto negativo en el desarrollo económico. R. FISMAN y R. GATTI, "Bargaining for bribes: the role of institutions", en S. ROSE-ACKERMAN (ed.), International Handbook on the Economics of Corruption, Edward Elgar Publishing, UK, 2006, pp. 127-139. La corrupción se señala también como una de las causas de "fallas en el mercado". L. PELLEGRINI, Corruption, Development and the Environment, cit., pp. 13, 149.

100 Cfr. N. KOFELE-KALE, "The Right to a Corruption-Free Society as an Individual and Collective Human Right: Elevating Official Corruption to a Crime under International Law", The International Lawyer, vol. 34, núm. 1, 2000, pp. 164-165. 
contemporáneo que, por definición, ha de basarse en el respeto al valor de la dignidad y dirigir su cometido hacia la garantía de los derechos, promoviendo el desarrollo social que los hace posibles.

Esta visión del Estado se traduce en obligaciones. Un Estado constitucional tiene la obligación de proteger la dignidad y garantizar los derechos, para lo cual debe crear un ambiente social en el que estos se disfruten, y debe actuar en contra de los fenómenos que los amenacen. Si la corrupción aparece hoy en día como uno de los grandes "enemigos" de los derechos, entonces el Estado constitucional tiene una obligación de combatirla y erradicarla ${ }^{101}$, para prevenir o para hacer cesar la violación de derechos que provoca.

Los argumentos mencionados, al hablar de que la corrupción es una violación de derechos en sí misma, se refieren a la corrupción generalizada o a gran escala, que con su proliferación impide el desarrollo y socava las bases de la legitimidad estatal; sin embargo, para efectos del deber de combatirla, la cuestión del grado es secundaria, pues hasta el más modesto acto de extorsión puede vulnerar la dignidad de quien lo sufre, del mismo modo que toda apropiación del patrimonio público mina el camino del desarrollo.

Dada esta naturaleza lesiva de la corrupción, algunas voces dentro de estos estudios van un paso más allá, proponiendo la existencia de un derecho humano nuevo: el derecho a una sociedad sin corrupción ${ }^{102}$. Este derecho humano particular es correlativo del deber estatal de combatir la corrupción; es también el derecho que resulta violado con cada caso de corrupción sin importar su grado.

Previamente a discutir esta propuesta, cabe mencionar que en esta revisión conceptual de la corrupción existe otra posición que plantea redefinir el fenómeno como "un crimen contra la humanidad" comparable con la tortura, el genocidio y otras prácticas que atentan contra la dignidad huma-

101 Así lo ha señalado expresamente la Corte Interamericana, con referencia a los Estados miembros de la Convención Americana sobre Derechos Humanos, en una sentencia reciente en la que se asocia una violación de derechos con la existencia de un "marco de corrupción". Textualmente el párrafo de interés señala: "La Corte recuerda que los Estados deben adoptar las medidas para prevenir, sancionar y erradicar eficaz y eficientemente la corrupción [Al respecto, véase, artículo 1 de la Convención de Naciones Unidas contra la Corrupción, entrada en vigor desde el 14 de diciembre de 2005 y ratificada por Guatemala el 3 de noviembre de 2006 y artículo II de la Convención Interamericana contra la Corrupción.]." Corte Interamericana de Derechos Humanos, Caso Ramírez Escobar y otros Vs. Guatemala. Fondo, Reparaciones y Costas, Sentencia de 9 de marzo de 2018, Serie C, núm. 351, párr. 242.

102 Véase infra Apartado 5. 
na ${ }^{103}$. Kofele-Kale desarrolla esta redefinición de la corrupción como un "crimen internacional" con una intención práctica: como una herramienta para perseguir el castigo, bajo la ley internacional y con las reglas de jurisdicción universal, de los grandes políticos corruptos, los gobernantes que expolian la riqueza de sus países y permanecen impunes. De este modo, no toda la corrupción resulta ser un crimen internacional, sino solo esos actos de "cleptocracia" o robo de la riqueza nacional a gran escala, que son actos de expoliación a los que este autor denomina "patrimonicidio", considerando que son delitos de excepcional magnitud y gravedad, que no tienen comparación con los sobornos a pequeña escala ${ }^{104}$.

Bantekas plantea esta tesis de la definición de la corrupción como un crimen internacional igualmente con un propósito práctico, como base de una propuesta para englobar la responsabilidad penal por actos de corrupción no solo de los gobernantes, sino también de los miembros de corporaciones multinaciona$\operatorname{les}^{105}$. Las debilidades de esta propuesta han sido señaladas por autores como Rose, quien puntualiza que el requisito mens rea de dolo directo necesario para establecer la responsabilidad en un crimen de esta magnitud, probablemente nunca se cumpliría en un caso de expoliación o gran corrupción ${ }^{106}$.

\section{LIBERTAD FRENTE A LA CORRUPCIÓN COMO UN DERECHO HUMANO}

\subsection{Argumentos en favor del reconocimiento del nuevo derecho}

Los argumentos que proponen reconceptualizar la corrupción como una violación de derechos humanos por sí misma, llevados un paso más ade-

103 En la $11^{\text {a }}$ Conferencia Internacional Anticorrupción, celebrada en Seúl en 2003, Kiraitu Murungi, Ministro de Justicia de Kenia, sostuvo que “la corrupción a gran escala debe ser designada como un crimen contra la humanidad, pues para muchos alrededor del mundo se encuentra en la misma categoría que la tortura, el genocidio y otros crímenes contra la humanidad que nos roban la dignidad humana". The Seoul Findings, cit.

104 N. KOFELE-KALE, "The Right to a Corruption-Free Society as an Individual and Collective Human Right: Elevating Official Corruption to a Crime under International Law", cit., pp. 152, 160, 163, 166, 174.

105 I. BANTEKAS, "Corruption as an International Crime and Crime against Humanity: An Outline of Supplementary Criminal Justice Policies", Journal of International Criminal Justice, vol. 4, 2006, pp. 466-484.

106 Cfr. C. ROSE, “Limitations of a Human Rights Approach to Corruption”, cit., p. 411.

ISSN: 1133-0937

DOI: https://doi.org/10.20318/dyl.2021.5855
DERECHOS Y LIBERTADES

Número 44, Época II, enero 2021, pp. 237-275 
lante, conducen a sostener la existencia de un derecho humano "nuevo", que se nombra derecho a un "mundo libre de corrupción"107, a una "sociedad libre de corrupción" 108 , a un "ambiente libre de corrupción"109, a "servicios públicos libres de corrupción" ${ }^{110}$, o simplemente "libertad frente a la corrupción" 111 "oficial" 112 .

Evidentemente, al no estar reconocido todavía en el derecho internacional de los derechos humanos ni en la generalidad de las constituciones nacionales, este derecho humano se afirma con una naturaleza moral ${ }^{113}$. Según se desprende de los escritos de sus proponentes, el derecho a una sociedad libre de corrupción tiene una doble fuente conceptual. Un primer argumento lo deriva de otros derechos ya reconocidos. Kofele-Kale, por ejemplo, lo enmarca en los derechos a la autodeterminación económica y al desarrollo. El nuevo derecho procede de estos dos derechos, según se entiende, porque ambos derechos son manifiestamente vulnerados por los graves actos de corrupción de los Estados expoliadores (como se refirió antes ${ }^{114}$ ). Adicionalmente, este autor sugiere que el derecho tiene una triple disposición: además de fluir de

107 Corruption and Human Rights: Making the Connection, cit., p. 3.

108 The Seoul Findings, cit.; N. KOFELE-KALE, "The Right to a Corruption-Free Society as an Individual and Collective Human Right: Elevating Official Corruption to a Crime under International Law", cit., p. 152.

109 Ibidem.

110 C. R. KUMAR, Corruption and Human Rights in India: Comparative Perspectives on Transparency and Good Governance, cit., p. 103.

111 A.B.SPALDING, "Corruption, Corporations, and the New Human Right", cit., p. 1365.

112 M. MURRAY y A. SPALDING, Freedom from Official Corruption as a Human Right, Governance Studies, The Brookings Institution, Washington, 2015, p. 1.

113 En este trabajo se sigue una concepción de los derechos humanos que distingue entre derechos "jurídicos" (o fundamentales) y derechos "morales". Los primeros están positivizados en tratados y constituciones; mientras que los derechos "morales" son producto de la reflexión moral. En la concepción que se sigue, estos derechos pueden coincidir en su contenido sustantivo, o no. Asimismo, los derechos morales no son "naturales" ni tienen las características que se asocian con esos "derechos naturales". Más bien, los derechos morales son proposiciones que expresan exigencias justificadas en razones morales. Esta concepción sigue, por ejemplo, a Wellman y a Cruz Parcero. Para el último, los derechos morales son una clase de "enunciados que implican alguna conclusión moral"; un derecho es "una especie de conclusión intermedia en el razonamiento práctico" basada en razones que apelan a intereses individuales o generales. Cfr. J. A. CRUZ PARCERO, Hacia una teoría constitucional de los derechos humanos, Instituto de Estudios Constitucionales del Estado de Querétaro, México, 2017, p. 35; C. WELLMAN, "Derechos: problemas filosóficos y propuestas de solución”, Anales de la Cátedra Francisco Suárez, núm. 44, 2010, pp. 265-280.

114 Véase supra Apartado 4.

DERECHOS Y LIBERTADES

ISSN: 1133-0937

Número 44, Época II, enero 2021, pp. 237-275

DOI: https://doi.org/10.20318/dyl.2021.5855 
los dos anteriores, también, de manera alternativa surge como un derecho por sí mismo ${ }^{115}$.

La conexión del nuevo derecho con los derechos marco a la autodeterminación económica y al desarrollo -o con cualesquiera otros- se da a partir de la necesidad: si la corrupción sistémica viola consistentemente ciertos derechos humanos, entonces parece que para gozar de esos derechos se necesita estar a salvo de la corrupción. Con respaldo en la teoría de los derechos de Shue, la afirmación de esta necesidad como un nuevo derecho moral se da por el principio de "transitividad", según el cual los derechos morales conllevan derechos a sus condiciones necesarias; asimismo, se respalda en el deber de garantizar, según el cual los derechos conllevan derechos al resguardo frente a las "amenazas estándar" que pueden interferir con su goce ${ }^{116}$. Entonces, si la corrupción sistémica es una "amenaza estándar" para todos los derechos ${ }^{117}$, el estar a salvo de la corrupción aparece como una condición necesaria para gozar de todos los derechos. Esa necesidad es lo que da contenido a la exigencia moral, que lleva a considerar a la libertad frente a la corrupción como un derecho por sí mismo. En un sentido teleológico, este nuevo derecho aparece como medio para proteger la dignidad humana. Esto, en tanto el nuevo derecho comparte la fundamentación de esos otros derechos ya reconocidos con los que se conecta, al constituir una norma necesaria para la protección de esos otros intereses ya reconocidos como fundados en el valor de la dignidad. Así, Kofele-Kale sostiene que el nuevo derecho es "inherentemente básico", porque de este "dependen" "la vida, la dignidad y otros valores humanos importantes". Sin este derecho, agrega, "esos valores esenciales pierden su significado" 118.

115 Cfr. N. KOFELE-KALE, “The Right to a Corruption-Free Society as an Individual and Collective Human Right: Elevating Official Corruption to a Crime under International Law", cit., p. 152.

116 Según la conocida propuesta de SHUE, un derecho moral proporciona un fundamento racional para la demanda justificada de que el goce real de un objeto será garantizado socialmente contra las "amenazas estándar". De este modo, si todo el mundo tiene derecho a cierto objeto, todo mundo tiene derecho también a la remoción de las más graves condiciones generales que podrían evitar o interferir severamente con el goce de eso a lo que la persona tiene derecho. Cfr. H. SHUE, Basic Rights: Subsistence, Afluence, and U.S. Foreign Policy, Princeton University Press, Princeton, 1996, pp. 13, 22, 32.

117 Desde su reconceptualización como una violación de derechos por sí misma. Véase supra Apartado 4.

118 N. KOFELE-KALE, "The Right to a Corruption-Free Society as an Individual and Collective Human Right: Elevating Official Corruption to a Crime under International Law", cit., pp. 152, 163. 
El derecho en comento también se deriva de derechos previstos en la Declaración Universal de Derechos Humanos, atendiendo no a una conexión de necesidad, sino de identidad. Spalding encuentra que la libertad frente a la corrupción es el reflejo de la libertad natural lockeana, que se convierte en libertad civil una vez instituido el gobierno de las leyes. De ahí que la libertad frente a la corrupción se entiende auténticamente como el "derecho definitorio de la sociedad civil" ${ }^{119}$. Esta libertad frente a la corrupción no se menciona en el texto de la Declaración, pero es un concepto que está implícito, que aparece "con otro nombre". Así, la "rebelión contra la tiranía y la opresión" del preámbulo define la idea de "gobierno legítimo" sujeto a las leyes desde Locke, y opuesto al gobierno de corrupción. También, los artículos $28^{120}$ y 29 de la Declaración definen el establecimiento de un orden encausado a la protección de los derechos, siendo preceptos que son "fundamentalmente" sobre la corrupción ${ }^{121}$.

Un segundo argumento sugiere que este derecho surge como "correlativo" 122 del deber estatal de erradicar la corrupción sistémica. Este deber que tiene el Estado es jurídico, pues se prevé en tratados internacionales como la CNUCC. También es un deber moral que resulta indiscutido dada la magnitud de la amenaza que la corrupción sistémica plantea para los valores protegidos por los derechos en general. Como este deber indiscutido es también incondicionado, se considera un deber "perfecto", porque "obliga estrictamente en todo momento" y, siendo así, según propone Cruz Parcero, es posible formularlo en términos de un derecho ${ }^{123}$.

De este modo, es dable decir que el deber de los Estados de erradicar la corrupción es correlativo del derecho de las personas que viven en el marco de los Estados a estar libres de corrupción. Desde una perspectiva moral "enriquecida" 124 , que se basa tanto en derechos como en deberes, sin establecer ninguna prioridad conceptual entre los elementos de esta dupla, se

119 A.B.SPALDING, "Corruption, Corporations, and the New Human Right", cit., p. 1402.

120 Particularmente el artículo 28, que señala: "Toda persona tiene derecho a que se establezca un orden social e internacional en el que los derechos y libertades proclamados en esta Declaración se hagan plenamente efectivos". Declaración Universal de Derechos Humanos. Resolución 217 A(III), Asamblea General, 10 diciembre 1948.

121 A.B. SPALDING, "Corruption, Corporations, and the New Human Right”, cit., p. 1402.

122 Sobre la correlatividad entre deberes y derechos morales véase J. A. CRUZ PARCERO, El lenguaje de los derechos. Ensayo para una teoría estructural de los derechos, Trotta, México, 2012, pp. 59-62.

${ }_{123}$ Cfr. Ibidem, p. 61.

124 Ibidem. 
puede seguir que el derecho existe en tanto existe el deber perfecto, aunque no se nombre o no se reconozca. En sentido normativo, existe ese derecho a una sociedad libre de corrupción, porque existe una posición desde la cual todo miembro de la sociedad puede reclamar justificadamente en cualquier momento el cumplimiento del objeto de ese deber.

Murray y Spalding exploran también esta relación entre la libertad frente a la corrupción oficial y los deberes del gobierno. Según refieren, aunque esta libertad no está reconocida aún como derecho en sentido jurídico, tiene un "equivalente funcional" en "la obligación fundamental que los gobiernos deben a cada individuo, en virtud de su condición de ser humano, que triunfa sobre otras consideraciones políticas, y cuya violación es una grave injusticia" ${ }^{125}$. La existencia de esta obligación, hallada primero en el iusnaturalismo de Locke, se complementa con un enfoque transcultural, particularmente con los hallazgos que los autores encuentran en las tradiciones políticas del confucionismo chino y la jurisprudencia islámica. En los valores dentro de estos paradigmas, el "equivalente funcional" de la libertad frente a la corrupción lockeana se halla en las obligaciones fundamentales de gobernanza: el deber de ser "virtuoso" como primer requerimiento del "buen gobierno" en Confucio, y el cultivo de la autodisciplina y la moralidad, junto a la prohibición de actos de corrupción, en el pensamiento islámico. Tras su revisión de esas tradiciones culturales, los autores concluyen que en ambas la corrupción se reconoce como "una violación de los más fundamentales principios de la sociedad civil y el buen gobierno". Este principio universal de la buena gobernanza sin corrupción es el equivalente funcional del derecho humano "independiente" a la libertad frente a la corrupción ${ }^{126}$.

De este modo, estos autores encuentran que el deber de erradicar la corrupción no es un deber estatal más, sino que aparece como el primer deber de todo gobierno. Con mayor precisión, este deber primario se ramifica en dos: la primera obligación de todo gobierno es no ser corrupto; la segunda, combatir los actos corruptos. Si estos deberes son fundamentales, según se dice, si son los primeros que deben regir la acción de todo Estado, entonces los derechos correlativos son también fundamentales, y son también los primeros que pueden reclamarse en una sociedad.

125 M. MURRAY y A. SPALDING, Freedom from Official Corruption as a Human Right, cit., p. 1.

126 Ibidem, pp. 10-11, 13. 
Con estas bases conceptuales se afirma el derecho a una sociedad libre de corrupción. La propuesta de su reconocimiento se acompaña también de argumentos utilitarios. Murray y Spalding sostienen que la conversión del principio universal de la buena gobernanza sin corrupción en un derecho humano "independiente" resulta útil porque fijaría un "mensaje inequívo$\mathrm{co}^{\prime \prime}$ de que la corrupción no es cultural ni un rasgo de la naturaleza humana, ratificando que la aplicación de las medidas anticorrupción es esencial. También ayudaría a proteger otros derechos, como la propiedad o la libertad, frente a su supresión por el abuso de oficiales corruptos ${ }^{127}$.

Kofele-Kale liga el nuevo derecho a su tesis sobre la corrupción como crimen internacional (como se refirió antes). Hay que precisar que, al hablar de una sociedad libre de corrupción, este autor se está refiriendo a los graves actos de expoliación y de robo de la riqueza nacional, ocurridos en múltiples países pobres durante las últimas décadas del siglo XX, los cuales considera actos de venalidad que no pueden colocarse en el mismo plano moral que el soborno, y que califican por sí mismos como violaciones de derechos humanos, pues efectivamente disuelven los valores de los derechos. Dados el auge y la impunidad de esa gran corrupción, para este autor resulta necesario encontrar el modo de colocarla "bajo alguna forma de disciplina internacional". De ahí que proponga el reconocimiento del nuevo derecho, como base para su propuesta ulterior de calificar la cleptocracia como crimen contra la humanidad ${ }^{128}$.

Por su parte, Kumar plantea la necesidad de reconocer este derecho -en el plano constitucional- con el propósito de colocar el tema de la corrupción en "el nivel central del discurso político". De este modo, en su propuesta, el nuevo derecho se prevé como una herramienta jurídico-política para potenciar el combate del problema, entre otras razones, porque a partir de su constitucionalización ha de generar obligaciones de combate para los distintos ámbitos del gobierno, además de empoderar a la sociedad civil para vigilar y asegurar la implementación de ese combate ${ }^{129}$.

127 Ibidem, pp. 1, 8, 13, 15.

128 N. KOFELE-KALE, "The Right to a Corruption-Free Society as an Individual and Collective Human Right: Elevating Official Corruption to a Crime under International Law", cit., passim.

129 Cfr. C. R. KUMAR, Corruption and Human Rights in India: Comparative Perspectives on Transparency and Good Governance, cit., pp. 105-107, 131. 


\subsection{Argumentos que niegan la posibilidad de considerar el nuevo derecho}

En principio, hay que precisar que la afirmación de la existencia de este derecho ha tenido poco eco dentro de los estudios del enfoque. El International Human Rights Committee for Protection (en adelante, IHRCP) señala que la propuesta tiene "méritos", pero no la retoma ${ }^{130}$. Junto con esta falta de atención, una primera crítica de carácter utilitario se plantea por autores como Peters, quien considera que no es necesario reconocer este derecho ${ }^{131}$, pues los derechos humanos ya reconocidos en los tratados bastan para capturar el daño causado por la corrupción ${ }^{132}$. Una segunda crítica de carácter conceptual puede formularse a partir de la discusión más general sobre los peligros de la "proliferación" y la "inflación" del lenguaje de los derechos, que advierten que el auge de derechos "falsos" puede producir la "devaluación" de los derechos "verdaderos" 133 .

La primera crítica no niega el vínculo entre derechos humanos y corrupción analizado en los apartados precedentes; simplemente, considera que para el logro del doble objetivo de protección de los derechos y combate a la corrupción que persigue el enfoque estudiado no se requiere llegar tan lejos como al reconocimiento de un nuevo derecho humano. A esta crítica hay que oponer la posible utilidad que el reconocimiento de este derecho tendría en el logro de esos objetivos. En primer lugar, en el plano del discurso político, el reconocimiento de este derecho contribuiría a consolidar la condena pública de la corrupción, que aún se ve debilitada por visiones relativistas sobre el carácter cultural o la inevitabilidad económica de la corrupción. Esto podría servir para dar un mayor impulso a las acciones anticorrupción, al generar un nuevo compromiso político en ese respecto.

Paralelamente, se contribuiría a generalizar un nuevo discurso sobre la corrupción enfocado en los daños que estos actos causan a las personas, al obstaculizar el goce de sus derechos. Posiblemente, para lograr estos efec-

130 Corruption and Human Rights: Making the Connection, cit., p. 3.

131 A. PETERS, "Corrupción y derechos humanos", cit., p. 32.

132 Cfr. C. ROSE, "Limitations of a Human Rights Approach to Corruption", cit., pp. 410-411.

133 Véase J. A. CRUZ PARCERO, “El debate sobre el abuso del concepto de derechos humanos”, en J. A. CRUZ PARCERO y G. ORTÍZ MILLÁN (comps.), Lenguaje, mente y moralidad. Ensayos en Homenaje a Mark Platts, Instituto de Investigaciones Filosóficas de la Universidad Nacional Autónoma de México, México, 2013, pp. 151-171. 
tos políticos no sea indispensable reconocer el nuevo derecho, según sugiere Peters; sin embargo, este reconocimiento aportaría un impulso adicional, porque supondría convertir las obligaciones anticorrupción de los Estados en deberes de primer orden, como lo son actualmente las obligaciones de cumplimiento de los tratados de derechos humanos.

En segundo lugar, en lo tocante a la acción institucional, el reconocimiento de este derecho permitiría diversificar las vías de respuesta jurídica a los actos de corrupción, complementando la justicia penal con los mecanismos de tutela de los derechos humanos, tanto internacionales como nacionales. La apertura a estos mecanismos de tutela permitiría poner énfasis en la reparación de los efectos negativos de los actos de corrupción, y no solo en la persecución y sanción. Esto, teniendo en cuenta la extensa jurisprudencia sobre reparación del daño que se ha desarrollado, por ejemplo, por la Corte Interamericana en el sistema interamericano, que enriquece el concepto limitado de reparación que ha prevalecido en el ámbito penal.

Conjuntamente, la diversificación de las vías institucionales abriría a los ciudadanos una puerta adicional para exigir justicia en los casos de corrupción, cuya dinámica sería sustancialmente distinta de la persecución penal. De reconocerse el nuevo derecho a una sociedad libre de corrupción, la eventual denuncia de que el Estado ha violado este derecho abriría un enjuiciamiento del propio Estado, que tendría que mostrar en el proceso que cumplió con las obligaciones de cumplimiento de este derecho (por ejemplo, las de respetar y garantizar, establecidas con base en la doctrina internacional). Este es un escenario muy distinto del régimen penal, dentro del cual los sujetos de enjuiciamiento por actos de corrupción son los individuos, y no el Estado.

En general, las razones utilitarias sostenidas para respaldar el reconocimiento de este nuevo derecho prolongan los planteamientos del conjunto de los textos del enfoque estudiado en este artículo. Explicitar el nuevo derecho sólo sería un paso más en la explicitación del vínculo entre corrupción y derechos humanos, que podría abonar a los objetivos de fortalecer la lucha anticorrupción al darle mayor relevancia, reposicionar el papel de las víctimas, o complementar el abordaje de la justicia criminal. Aquí, por supuesto, las expectativas dependen de cuánta efectividad se reconozca al lenguaje de los derechos humanos y al orden institucional para su protección, ya sea nacional o internacional. Las reticencias sobre la necesidad de reconocer este nuevo derecho pueden ser por exceso de celo en cuidar que este lenguaje y 
esas instituciones no debiliten su efectividad al ir más allá de sus límites; o bien, por escepticismo y "falta de fe" en ese lenguaje, al considerar que los derechos humanos son un aderezo retórico que nada efectivo puede aportar a la arena anticorrupción.

Por lo que hace a la segunda crítica, esta sugiere que no es posible reconocer este derecho humano a una sociedad libre de corrupción, porque el reclamo que expresa no reúne los requerimientos conceptuales para calificar como un derecho humano; por ejemplo, la característica de la universalidad. Enfrentar esta crítica requiere adoptar en primer momento una concepción que establezca cuáles son los rasgos definitorios de los derechos humanos, para después evaluar si la exigencia que se propone como derecho reúne esos rasgos. Para esto, la postura de este artículo se aleja de las concepciones fundacionalistas ortodoxas, que definen los derechos humanos a partir de las características de los "derechos naturales" o los derechos individuales y libertades negativas del primer liberalismo ${ }^{134}$, dado lo cual, excluyen a grupos de derechos ya reconocidos en la práctica jurídica, como los sociales y económicos, entre otros ${ }^{135}$.

Como ya se señaló, en la concepción que aquí se sigue, los derechos humanos (de naturaleza moral como el que se discute) se conciben como proposiciones o juicios que expresan exigencias justificadas en razones morales ${ }^{136}$. Según esto, cuando se afirma que alguien tiene un derecho humano a algo, se está diciendo que existen bastantes razones para considerar que ese alguien y junto con él todos los seres humanos, tiene algo fundamental que exigir a los demás. De acuerdo con esta concepción, un derecho humano tiene como contenido una exigencia justificada que, además de expresar un interés o una preocupación humana, presenta los rasgos característicos de la fundamentalidad y la universalidad ${ }^{137}$.

134 En general, son las fundamentaciones éticas liberales de los derechos las que se muestran inflexibles y proponen amurallar el concepto, proponiendo criterios cerrados para distinguir los derechos humanos verdaderos (generalmente, coincidentes con los derechos naturales del primer liberalismo) de los falsos, advirtiendo que estos constituyen un peligro. Por ejemplo, véase J. GRIFFIN, On Human Rights, Oxford University Press, Oxford, 2008, p. 92.

135 Para las concepciones ortodoxas, incluso derechos previstos en la propia Declaración Universal no son derechos humanos. Véase C. R. BEITZ, The Idea of Human Rights, Oxford University Press, Oxford, 2009, pp. 50-51.

136 Cfr. C. WELLMAN, "Derechos: problemas filosóficos y propuestas de solución”, cit., p. 273; J. A. CRUZ PARCERO, Hacia una teoría constitucional de los derechos humanos, cit., p. 35.

137 Esto es una versión reducida de la visión de Pogge, quien propone que el concepto de derecho humano en sentido moral contiene seis elementos "incontrovertidos". Para que 
Sin desarrollar a fondo estas nociones, lo que excede el propósito del artículo, se afirma que la exigencia de vivir en una sociedad libre de corrupción reúne esos rasgos. En primer lugar, expresa una preocupación humana relevante: estar a salvo del ejercicio abusivo del poder, tanto político como económico. Este abuso del poder, que se ha manifestado en distintas épocas como tiranía o explotación económica, se manifiesta en las sociedades actuales democráticas (o formalmente no autoritarias, cuando menos) como corrupción. El derecho en examen recoge el interés humano de ser reconocido como un agente que puede exigir a quienes detentan cualquier clase de poder en la sociedad, que no realicen prácticas de abuso que supongan la expoliación o instrumentalización de quienes están sujetos a su poder.

Esta preocupación es fundamental porque tiene una conexión con la dignidad humana, en tanto aparece como una condición necesaria para su protección. En general, suele aceptarse la idea de que los derechos humanos son medios para proteger o realizar el fin de la dignidad humana. En esa medida, si el abuso de poder que constituye la corrupción es una amenaza para el goce de otros derechos humanos -como han empezado a reconocer los estudios del enfoque estudiado-, su proliferación se vuelve una amenaza para la propia dignidad que los derechos buscan proteger.

Entendida la corrupción como una amenaza para los derechos, aparece que para el goce de estos se necesita estar a salvo de la corrupción. Esa necesidad justifica la nueva exigencia que se propone como derecho. Adicionalmente, se encuentra que en los propios actos de corrupción hay un elemento que resulta lesivo de la dignidad. La proliferación de la corrupción es por sí misma un fenómeno humillante para los miembros de una sociedad, quienes han de padecer que sus propios gobernantes abusen del ejercicio del poder para medrar ${ }^{138}$. Esta corrupción niega el valor como sujetos de

un derecho humano califique como tal, ha de: 1) expresar "intereses morales fundamentales"; 2) expresar "preocupaciones morales de peso"; 3) expresar preocupaciones morales que "se centran en seres humanos", como únicos tenedores del "estatus moral especial asociado"; 4) con respecto a ese estatus y esas preocupaciones, considerar la igualdad para todos los seres humanos; 5) expresar "preocupaciones morales cuya validez es irrestricta", siendo "vinculantes" sin importar la época, cultura o tradición; y 6) expresar preocupaciones "ampliamente compartibles", esto es, comprensibles y apreciables por personas de distintas épocas y culturas. T. POGGE, Hacer justicia a la humanidad, Instituto de Investigaciones Filosóficas de la Universidad Nacional Autónoma de México, Comisión Nacional de los Derechos Humanos, Fondo de Cultura Económica, México, 2009, pp. 75-76.

138 Un ejemplo trágico de la humillación que produce la corrupción es el caso de Mohamed Bouazizi, quién en 2010 se inmoló en Túnez como última forma de protesta ante el 
los desempoderados, que se convierten en víctimas de formas institucionalizadas de expoliación.

Finalmente, se considera que también puede predicarse el carácter universal de la exigencia de vivir en un régimen libre de corrupción: se trata de un reclamo que podría ser sostenido por todos los seres humanos, en distintas culturas y sociedades ${ }^{139}$, con base en el respeto debido que cada uno ha de guardar a los otros, por consideración a su igual dignidad humana. Si la corrupción de quienes detentan poder es humillante y una amenaza para los derechos de los desempoderados, entonces todos los seres humanos están en una posición de exigir a los detentadores de poder que se abstengan de realizar actos de corrupción. Esta exigencia presenta también la cualidad de que puede hacerse recíprocamente: todos los seres humanos podrían sostener frente a los demás el reclamo de que se establezcan regímenes sociales libres de corrupción, del mismo modo que se exigen otras condiciones necesarias para gozar de bienes básicos, sin que la afirmación de esta exigencia para unos suponga su negación para otros.

De este modo, de acuerdo con una concepción no fundacionalista de los derechos humanos como la que se ha esbozado, alejada de las visiones ortodoxas en las que resuenan los rasgos absolutos de los derechos naturales, hay elementos para sostener que la exigencia examinada en este artículo califica como un derecho humano. Para cerrar este apartado cabe añadir que, lo que en realidad está a discusión en este renglón, es el carácter abierto o cerrado de los catálogos de derechos humanos. Como se espera haber dejado claro, la concepción de este artículo ve con buenos ojos el fenómeno de expansión de

abuso de poder de los oficiales corruptos. Su ejemplo fue seguido por docenas de personas en el movimiento de la Primavera árabe. Cfr. M. MURRAY y A. SPALDING, Freedom from Official Corruption as a Human Right, cit., p. 4.

139 En la concepción que sigue este artículo, la idea de universalidad de los derechos está alejada de la interpretación ortodoxa, que ha sostenido el carácter ahistórico (indiferente a los cambios de las sociedades humanas en el tiempo) y transcultural (indiferente a las diferencias culturales en el momento actual) de los derechos. Resulta más plausible la interpretación de la universalidad que da la tesis del "reconocimiento", según la cual, el fundamento de la universalidad de los derechos se sustenta en dos elementos: primero, la "capacidad" moral de cada uno de los hombres de ver a cada uno de los otros como individuos "dignos de reconocimiento"; y segundo, la "disposición" a efectuar ese reconocimiento en la práctica. Cfr. C. MENKE y A. POLLMANN, Filosofía de los derechos humanos, Herder, Barcelona, 2010, p. 65. A diferencia del modelo ortodoxo, para esta perspectiva la universalidad tiene solamente grado de pretensión. La universalidad de los derechos se asume como un proyecto o aspiración, que ha de ser objeto de un eventual consenso futuro.

ISSN: 1133-0937

DOI: https://doi.org/10.20318/dyl.2021.5855
DERECHOS Y LIBERTADES

Número 44, Época II, enero 2021, pp. 237-275 
los derechos que se presenta en la práctica institucional actual, en la cual los distintos actores sociales, al apropiarse del lenguaje de los derechos humanos, constantemente presentan nuevos reclamos como candidatos a entrar en esa categoría.

\section{RECONOCIMIENTO DEL DERECHO FUNDAMENTAL A UNA SOCIEDAD LIBRE DE CORRUPCIÓN EN LATINOAMÉRICA}

La explicitación de los vínculos entre derechos humanos y corrupción ha sido tema de discusión en algunas jurisdicciones nacionales, como en la India y en Sudáfrica ${ }^{140}$. En el constitucionalismo latinoamericano reciente, destacan los casos de México y particularmente el de Ecuador, que ya ha llevado a su texto fundamental estos planteamientos, en el reconocimiento de un derecho fundamental a una sociedad libre de corrupción.

En México, la Constitución Política de la Ciudad de México (capital de la República ${ }^{141}$ ) promulgada en 2017 no menciona textualmente el derecho a una sociedad libre de corrupción, pero este se encuentra implícito en el reconocimiento -novedoso en el país- de un "derecho a la buena administración". Este derecho fundamental se define como un principio organizador del ejercicio del poder ${ }^{142}$ y es también un marco que comprende diversos sub-derechos ${ }^{143}$. La Constitución local establece que la garantía de este dere-

140 En una sentencia de 2012, la Suprema Corte de la India sostuvo que la corrupción viola indirectamente los derechos humanos, mientras que la corrupción sistémica es una violación de los derechos humanos en sí misma. Por su parte, la Corte Constitucional de Sudáfrica ha sostenido desde 2000 que la corrupción socava el compromiso constitucional con la dignidad humana, el logro de la igualdad y el avance de los derechos humanos y libertades. Apud A. PETERS, “Corruption as a Violation of International Human Rights”, cit., p. 1258.

141 En el federalismo mexicano, cada estado de la República cuenta con una Constitución local que define su organización política interna.

142 "El ejercicio del poder se organizará conforme a las figuras de democracia directa, representativa y participativa, con base en los principios de interés social, subsidiariedad, la proximidad gubernamental y el derecho a la buena administración". Constitución Política de la Ciudad de México, Gaceta Oficial de la Ciudad de México, 5 de febrero de 2017, art. 3.3.

143 "A. Derecho a la buena administración pública. 1. Toda persona tiene derecho a una buena administración pública, de carácter receptivo, eficaz y eficiente, así como a recibir los servicios públicos de conformidad con los principios de generalidad, uniformidad, regularidad, continuidad, calidad y uso de las tecnologías de la información y la comunicación. 2. Las autoridades administrativas deberán garantizar la audiencia previa de los gobernados frente a toda resolución que constituya un acto privativo de autoridad. En dichos supuestos, deberán resolver de manera imparcial y equitativa, dentro de un plazo razonable y de confor- 
cho consiste en el "debido ejercicio y la probidad en la función pública", lo cual, entre otros principios como honestidad, transparencia, eficiencia y profesionalismo, conlleva un gobierno "que procure el interés público y combata la corrupción" ${ }^{\prime 144}$.

Independientemente de cómo se ha interpretado este derecho a la buena administración en otras latitudes ${ }^{145}$, en México se le asocia fundamentalmente con la política anticorrupción. Aceves refiere que el surgimiento de este derecho en la Constitución de la Ciudad de México refleja parte del "cansancio" de los mexicanos frente al "mal desempeño" de los gobernantes, caracterizado por los cotidianos casos de corrupción y por la constatación de que los recursos públicos no se traducen en desarrollo económico y social, ni en la satisfacción de las necesidades de seguridad, salud o educación, siendo estas expresiones de un "mal gobierno" 146. Frente a ese "mal gobierno", la constitución local busca establecer los rasgos que ha de tener un "buen gobierno", entre los cuales el tema del combate a la corrupción ocupa un lugar fundamental. De ahí que en el propio texto constitucional -tanto en la ciudad de México como también en la Constitución política general- se haya previsto la creación de estructuras orgánicas denominadas "Sistemas

midad con las formalidades esenciales del procedimiento. 3. En los supuestos a que se refiere el numeral anterior, se garantizará el acceso al expediente correspondiente, con respeto a la confidencialidad, reserva y protección de datos personales. 4. La ley determinará los casos en los que deba emitirse una carta de derechos de los usuarios y obligaciones de los prestadores de servicios públicos. Las autoridades conformarán un sistema de índices de calidad de los servicios públicos basado en criterios técnicos y acorde a los principios señalados en el primer numeral de este apartado.". Constitución Política de la Ciudad de México, cit., art. 7A.

144 "Garantía del debido ejercicio y la probidad en la función pública. 1. Se garantiza el derecho a la buena administración a través de un gobierno abierto, integral, honesto, transparente, profesional, eficaz, eficiente, austero, incluyente, y resiliente que procure el interés público y combata la corrupción.". Constitución Política de la Ciudad de México, cit., art. 60.1.

145 Por ejemplo, en Europa, se entiende relacionado con la función administrativa y el correcto procedimiento administrativo. Véase Carta de los Derechos Fundamentales de la Unión Europea (2000/C 364/01), Diario Oficial de las Comunidades Europeas, 18 de diciembre de 2000, art. 41; J. RODRÍGUEZ-ARANA, "La buena administración como principio y como derecho fundamental en Europa", Misión Jurídica. Revista de Derecho y Ciencias Sociales, núm. 6, 2013, pp. 23-56.

146 Cfr. L. ACEVES DÍAZ DE LEÓN, “El derecho a la buena Administración Pública en la Constitución Política de la Ciudad de México y su aporte a la gobernanza”, en J. A. LÓPEZ VELARDE CAMPA (coord.), La gobernanza en la Ciudad de México. Visiones multidisciplinarias, Escuela de Administración Pública de la Ciudad de México, Asamblea Legislativa del Distrito Federal, Instituto de Investigaciones Jurídicas de la Universidad Nacional Autónoma de México, México, 2018, pp. 17-38. 
Anticorrupción", que se establecen como la última gran solución del Estado mexicano para enfrentar el problema ${ }^{147}$.

De este modo, al asumir que la política anticorrupción es pilar de la idea de un "buen gobierno" y garantía del derecho a la buena administración, la Constitución de la Ciudad de México ratifica el deber estatal de combatir y erradicar la corrupción en todos sus ámbitos. El derecho a una sociedad libre de corrupción no aparece textualmente ${ }^{148}$, pero los diversos principios que componen la garantía del "debido ejercicio" y la "probidad en la función pública", establecen con claridad una expectativa de que los servidores públicos han de desempeñar su encargo con apego a la ley, observando valores de honestidad, con respeto a los derechos humanos y al margen de toda práctica corrupta.

Por lo que hace a Ecuador, el último constituyente de este país adelantó varios pasos más, al reconocer de manera expresa en la Constitución de 2008 un complejo derecho de los habitantes del Estado que incluye, entre otras previsiones, el "vivir en una sociedad democrática y libre de corrupción" ${ }^{149}$. Esta previsión reformula lo que ya se había señalado en la Constitución ecuatoriana de 1998, que en el mismo numeral incluyó el deber estatal de garantizar "la administración pública libre de corrupción". Además, la Constitución de 2008 prevé la estructura orgánica para el combate del problema; siguiendo las bases que ya se habían señalado en 1998, las labores anticorrupción se encargan a un órgano ciudadano: el "Consejo de Participación Ciudadana y Control Social", que forma parte de la "Función de Transparencia y Control

147 Véanse R. C. FONSECA, “Mexico's National Anti-Corruption System: Reaching the Finish Line?", University of Miami Inter-American Law Review, vol. 50, núm. 2, 2019, pp. 85-121; J. TAPIA TOVAR, Nuevo Sistema Nacional Anticorrupción, Porrúa, México, 2017.

148 Cabe afirmar que la discusión sobre este derecho empieza a "estar en el aire" en el país. En el ámbito de los órganos judiciales federales mexicanos, se ha dado ya alguna sentencia en la que se hace mención de un "derecho fundamental de los ciudadanos a vivir en un Estado y sociedad libre de corrupción", lo que implica "un ambiente libre de corrupción en el que todos los funcionarios públicos desempeñen su labor con honradez, honestidad ética y transparencia". De este derecho, la "garantía institucional y procesal" es el Sistema Nacional Anticorrupción (Juicio de Amparo: 589/2018, Juzgado Octavo de Distrito en Materia Administrativa en la Ciudad de México). En contra de esta decisión, véase: J. M. REYES y J. J. GARZA ONOFRE, "Magistrados anticorrupción: una sentencia retórica y de meros buenos deseos", Nexos, 7 de agosto de 2018.

149 "Son deberes primordiales del Estado: (...) 8. Garantizar a sus habitantes el derecho a una cultura de paz, a la seguridad integral y a vivir en una sociedad democrática y libre de corrupción." Constitución de la República del Ecuador, Registro Oficial, núm. 449, 20 de octubre de 2008 , art. 3.8 . 
Social", una suerte de cuarto poder ${ }^{150}$ popular, de igual jerarquía a los tres poderes tradicionales del Estado ${ }^{151}$.

Las Constituciones de Ecuador de 1998 y 2008 -y en cierta medida también la de la Ciudad de México de 2017- forman parte del grupo de leyes fundamentales promulgadas en la época reciente en la región, que se han identificado como parte de un "nuevo" 152 constitucionalismo latinoamericano, también llamado constitucionalismo "transformador"153. Particularmente, la constitución ecuatoriana de 2008 ha sido considerada una de las más "avanzadas" 154 , entre otros aspectos, por su catálogo amplísimo de derechos, y por introducir nociones de la cosmovisión indígena andina (como el concepto de "buen vivir" o Sumak Kawsay ${ }^{155}$ ) al escenario constitucional.

Este concepto andino de "buen vivir" constituye un principio normativo base, a la luz del cual debe interpretarse el catálogo de derechos y los deberes estatales previstos en la Constitución ecuatoriana de 2008. Desarrollar el contenido de este principio excede el propósito de este trabajo; para lo que aquí interesa, basta señalar que el "buen vivir" implica un modelo de desarrollo económico y social "alternativo" al de la globalización neoliberal, que enriquece el discurso de los derechos humanos con elementos de carácter intercultural, solidario, comunitario y de convivencia armónica con el medioambiente ${ }^{156}$. Al intersecarse este principio con el derecho fundamental en estudio, se configura un "derecho al buen vivir en una sociedad libre de

150 El establecimiento de un modelo de "Cuarto poder ciudadano anticorrupción" se planteó en los debates del constituyente de la ciudad de México, pero no trascendió al texto aprobado. Véase I. E. SANDOVAL BALLESTEROS, “Análisis crítico del Título sexto sobre combate a la corrupción y buen gobierno de la Constitución Política de la Ciudad de México", Boletín Mexicano de Derecho Comparado, año XLX, núm. 152, 2018, pp. 869-912.

151 Véanse A. GRIJALVA JIMÉNEZ, Constitucionalismo en Ecuador, Corte Constitucional para el Período de Transición, Quito, 2012, p. 33; A. NOGUERA FERNÁNDEZ, "Participación, Función Electoral y Función de Control y Transparencia Social", en R. ÁVILA SANTAMARÍA et al. (eds.), Desafíos constitucionales. La Constitución ecuatoriana del 2008 en perspectiva, Ministerio de Justicia y Derechos Humanos, Quito, 2008, pp. 133-157.

152 R. MARTÍNEZ DALMAU, “Constitucionalismo democrático e innovación constitucional en Ecuador: la Constitución de 2008”, Revista Diálogos de Saberes, núm. 47, 2017, pp. 81-102.

153 A. V. BOGDANDY, "Ius Constitutionale Commune en América Latina: una mirada a un constitucionalismo transformador", Revista Derecho del Estado, núm. 34, 2015, pp. 3-50.

154 R. MARTÍNEZ DALMAU, "Constitucionalismo democrático, cit., pp. 81-102.

155 Véase C. SILVA PORTERO, “Qué es el buen vivir en la Constitución?”, en R. ÁVILA SANTAMARÍA (ed.), La Constitución del 2008 en el contexto andino. Análisis desde la doctrina y el derecho comparado, Ministerio de Justicia y Derechos Humanos, Quito, 2008, pp. 111-154.

156 Cfr. ibidem; A. GRIJALVA JIMÉNEZ, Constitucionalismo en Ecuador, cit., pp. 45-50.

ISSN: 1133-0937

DOI: https://doi.org/10.20318/dyl.2021.5855
DERECHOS Y LIBERTADES

Número 44, Época II, enero 2021, pp. 237-275 
corrupción", que exige del Estado una política anticorrupción subordinada al objetivo de promover ese modelo de desarrollo y bienestar autóctono.

Los casos de la Ciudad de México y de Ecuador muestran cómo el tema de la corrupción se ha incorporado a las discusiones de orden constitucional y en este marco, su vínculo con los derechos se hace manifiesto. Es interesante resaltar que se trata de dos ejemplos desde el "sur global", que -especialmente en el caso de Ecuador y en menor medida en el caso de la Ciudad de México- se apropian del nexo conceptual entre corrupción y derechos humanos, y lo incluyen en documentos constitucionales que muestran un fuerte carácter identitario, que ni por asomo se ven como imposiciones ideológicas externas, sino al contrario, se conciben como alternativas locales frente a la hegemonía del discurso de los derechos individuales y el desarrollo neoliberal del "norte global".

Esto último viene a colación porque una de las críticas a la vinculación entre el discurso de los derechos humanos y la política anticorrupción advierte de su utilización como una forma más de relegitimar el control de los países del "norte" sobre los del "sur", dando nuevo impulso a la imposición del modelo de desarrollo de mercado propugnado por los actores de la política anticorrupción global ${ }^{157}$. El caso de Ecuador refuta esta crítica, en tanto muestra que, al hablar de política anticorrupción, el norte y el sur globales pueden estar empezando a hablar de cosas distintas. Los deberes de combatir el abuso de poder y erradicar la corrupción sistémica son los mismos en el norte y en el sur. Sin embargo, ya en la ejecución de las obligaciones anticorrupción, estas no tienen forzosamente que enmarcarse en las recomendaciones formuladas por los promotores del desarrollo de mercado, sino que bien pueden orientarse hacia modelos de desarrollo alternativos en el marco de Estados pluriculturales que enriquecen con su visión el lenguaje de los derechos. De este modo, la lucha contra la corrupción puede cambiar de orientación y subordinarse a la defensa de los derechos de las personas, y ya no a los intereses del mercado global.

\section{CONCLUSIÓN}

Hay elementos suficientes para sostener la existencia de un derecho humano a una sociedad libre de corrupción sistémica. Este derecho, hasta ahora

157 Véanse M. GOODWIN y K. ROSE-SENDER, “Chapter X. Linking corruption and human rights: an unwelcome addition to the development discourse", en M. BOERSMA y H. NELEN (eds.), Corruption \& Human Rights, cit., pp. 221-240; B. RAJAGOPAL, "Corruption, Legitimacy, cit., p. 506. 
únicamente de carácter moral, tiene una doble base conceptual. Por un lado, deriva de otros derechos humanos ya reconocidos por el Derecho internacional de los derechos humanos, pues es una condición necesaria para el goce de estos. Por otro lado, es un derecho correlativo del deber indiscutido del Estado, fundado en documentos del derecho internacional como la CNUCC, de tomar las medidas adecuadas para prevenir, sancionar y erradicar la corrupción.

Aunque la reivindicación de este derecho es una propuesta minoritaria dentro de los estudios del enfoque basado en derechos humanos sobre la corrupción, la propuesta es armónica con las dos tesis centrales que plantean estos estudios: que la corrupción produce un impacto negativo en el goce de los derechos humanos, y que este impacto se presenta siempre, con todos los casos de corrupción, aunque no se pueda explicitar cómo sucede en cada caso. Reconocer el derecho propuesto es pertinente para establecer con claridad ese vínculo existente entre corrupción y derechos humanos en el mundo contemporáneo.

Posiblemente, el reconocimiento de este derecho moral como derecho humano mediante su progresiva expresión jurídica, sea nacional o internacional, tendrá pocas consecuencias prácticas inmediatas, además del efecto retórico de vestir la lucha anticorrupción con el lenguaje de los derechos humanos. Sin embargo, este efecto retórico es por sí mismo importante, en tanto la apelación a la constitución y a los tratados de derechos da bases para una mayor movilización ciudadana, que es lo único que en países latinoamericanos como México ha permitido tener avances en la lucha contra la corrupción. En este sentido, resultaría útil para poner el foco en la responsabilidad del Estado, y ya no solo en la responsabilidad de los agentes individuales.

Con miras a la positivización de este derecho humano a una sociedad libre de corrupción, queda por explorar cómo se armonizaría con los regímenes de obligaciones estatales, tanto las que derivan de los tratados de derechos humanos, como las que se fundan en los documentos internacionales anticorrupción.

Roberto Carlos Fonseca Luján Universidad Nacional Autónoma de México

Facultad de Derecho.

Circuito interior $s / n$,

Ciudad Universitaria. Coyoacán. C.P. 04510.

Ciudad de México, México. e-mail:rfonsecal@derecho.unam.mx

ISSN: 1133-0937

DOI: https://doi.org/10.20318/dyl.2021.5855
DERECHOS Y LIBERTADES

Número 44, Época II, enero 2021, pp. 237-275 